\title{
Climatology and physical mechanisms of the tropospheric warm cores over the Tibetan Plateau and its vicinity
}

\author{
Ke Shang ${ }^{1,2} \cdot{\text { Xiaodong } \operatorname{Liu}^{1,2,3} \cdot \text { Buwen Dong }}^{4}$ (1)
}

Received: 11 January 2021 / Accepted: 23 March 2021 / Published online: 16 April 2021

(c) The Author(s) 2021

\begin{abstract}
The frequently observed tropospheric warm cores over the Tibetan Plateau (TP) are unique climate phenomena and are crucial to the Asian summer monsoon development. However, their climatological structure and formation mechanisms remain elusive and inconsistent among previous studies. In this work, two vertically separated warm cores, the upper-level warm cores (ULWCs) and lower-level warm cores (LLWCs), are identified based on the zonal temperature deviation. The LLWCs are basically confined below $450 \mathrm{hPa}$, and the ULWCs are mostly observed at 200-400 hPa. The active region of the LLWCs is generally within the TP domain and characterized by regional patches with high frequency occurrences. In contrast, the active region of the ULWCs is featured by a zonally elongated band along the southern TP. The physical mechanisms for the formations of these two distinct types of warm cores are revealed: the LLWCs are mainly generated and maintained by the surface diabatic heating, while the ULWCs are dominated by the large-scale circulation associated with the convection over the Indo-Pacific warm pool. During March-June, the ULWCs within the TP domain occur most frequently and the intensities attain their maxima. In March-April, the ULWCs are mainly determined by the TP adiabatic subsidence induced by the convection over the Indo-Pacific warm pool. In May-June, the warm advection induced by westerlies generates the downstream ULWCs and enhances the ULWCs formed in previous months. Hence it might be inappropriate in traditional view to attribute the tropospheric warm cores around the TP solely to the direct thermal effect of the elevated topography.
\end{abstract}

Keywords Warm core $\cdot$ Tibetan Plateau $\cdot$ Climatology $\cdot$ Physical mechanism

\section{Introduction}

The Tibetan Plateau (TP), long been known as the "third pole of the Earth" and the "roof of the world", has one of the most complex geographical features in the world. As an elevated heat source, the TP acts directly on the middle troposphere and generates strong thermal contrast with the

Xiaodong Liu

liuxd@loess.llqg.ac.cn

$\triangle$ Buwen Dong

buwen.dong@ncas.ac.uk

1 SKLLQG, Institute of Earth Environment, Chinese Academy of Sciences, Xi' an 710061, China

2 University of Chinese Academy of Sciences, Beijing 100049, China

3 CAS Center for Excellence in Tibetan Plateau Earth Sciences, Beijing 100101, China

4 National Centre for Atmospheric Science, University of Reading, Reading RG6 6BB, UK adjacent non-elevated atmosphere. It has been suggested to play a fundamental role in generating and maintaining the Asian summer monsoon and shaping the Earth's climate (Flohn 1957; Ye et al. 1957; Ding 1992; Wu et al. 2007).

Various indices have been developed to depict the thermal condition of the TP, for instance, air temperature ( $\mathrm{Li}$ and Yanai 1996; Wang et al. 2008), surface sensible heating (Duan et al. 2013) and atmospheric heat source (Yanai et al. 1992). Among them, the index defined using air temperature is extensively applied in many studies as it intuitively and directly reflects the TP thermal condition. Often cited (Chou 2003; Li et al. 2004; Li and Pan 2006) is the index set up by Li and Yanai (1996), who calculated the vertically averaged temperature (500-200 hPa) above the TP and showed the internal connection between the TP thermal condition and the onset and variability of Asian summer monsoon. The temperature-related warm cores are also regarded as important indicators of the thermal state of the TP and are crucial in modulating the establishment and maintenance of the Asian summer monsoon circulation as well as the 
variability of Asian monsoon precipitation ( $\mathrm{Li}$ and Yanai 1996; Liu and Yanai 2001; Tamura et al. 2010). In summer, the whole troposphere over the TP is occupied by warm air mass, with the temperature maximum located over the TP (Ye and Gao 1979). By using an 80-day data (16 April-4 July 1979) obtained from First Global Atmospheric Research Program (CARP) Global Experiment (FGGE), He et al. (1987) found that the warm center on the TP is a unique feature observed in the middle troposphere and is related to the topographic heat low. Furthermore, in addition to FGGE II-b data, the data obtained at additional stations during the Chinese Qinghai-Xizang Plateau Meteorology Experiment (QXPMEX) have been fully included in the research of Yanai et al. (1992). They examined the detailed warming process for a 9-month period and confirmed that the warm cores exist in the middle troposphere due to the near-surface heating of the TP in spring. Later, based on a 14-year climatological analysis in the mean summer temperature field at the 200-500 hPa layer, Li and Yanai (1996) found that "a huge warm air mass is centered on South Asia with the maximum temperature $\left(\geq-22{ }^{\circ} \mathrm{C}\right)$ over the southern TP". They proved that an "explosive" growth of this warm air led to the change in meridional temperature gradient and the onset of the planetary-scale Asian summer monsoon.

Up to now, it is still debatable regarding the formation of this tropospheric temperature maximum. The traditional views linked the tropospheric temperature variation to the direct heating effect of elevated topography. It was suggested that the whole air column was heated bottom-up by the ground surface through upward turbulent sensible heating (Luo and Yanai 1984; Yanai and Li 1994; Li and Yanai 1996), condensation latent heat release (Nitta 1983; Ueda et al. 2003; Taniguchi and Koike 2007), and surface net radiation (de Kok and Immerzeel 2019). Numerous general circulation models (GCMs) validated the dependency of air temperature variation on the uplift effect of the TP (Hahn and Manabe 1975; Kuo and Qian 1981; Zheng and Liou 1986; Liu and Yin 2002). Hahn and Manabe (1975) used an eleven-level model to compare climates under conditions with and without the topography. Their results indicated that in the model with mountains, much higher temperature was maintained in the middle and upper troposphere over the TP. By employing the CCM1 (R15L7)-LNWP spectral model, Zheng and Liang (1999) proved that the orographic effect of the TP profoundly influenced the atmospheric heating in early boreal summer. As an elevated heat source in the middle troposphere, the huge orography of the TP can produce a warm center $(224 \mathrm{~K})$ at $200 \mathrm{hPa}$ and increase the air temperature by $7 \mathrm{~K}$ under the condition with the presence of the TP than without the TP.
In recent years, however, there are some evidence indicating that the formation of the warm cores may not entirely be the result of the TP heating, but rather the outcome of other external thermal forcing. Boos and Kuang (2010) showed that the Himalayas, the southern edge of Tibet, blocked hot moist air over North India from mixing with cool dry air inland, so that the upper troposphere temperature maximum was coupled to the highest entropy sub-cloud layer in northern India. In that case, the thermal forcing of continental India was vital to determine the position and amplitude of the upper warm center. Wu et al. (2015) noted that the appearance and variation of the summertime upper tropospheric warm maximum was a complicated large-scale thermodynamic issue. They thought that the warm center could be attributed to the combined effect of strong convective latent heating associated with the Asian monsoon rainfall, and the longwave radiation cooling over the western Eurasia. Tamura et al. (2010) analyzed the upper tropospheric warming around the Tibetan Plateau during the onset phase of Asian summer monsoon and suggested that the temperature increase was due to the local adiabatic warming that was closely associated with the local Hadley circulation. Forsythe et al. (2017) and Li et al. $(2018,2019)$ proposed that adiabatic heating and cooling, caused by the "Karakoram Vortex/Western Tibetan Vortex", was the main driver of tropospheric temperature variations over the TP.

Previous works have recognized the warm cores around the TP as a spectacular phenomenon, but the timespans of the data were considerably short, and most of the past studies tended to focus only on boreal summer season. So far, little attention has been devoted to the climatology of the warm cores, and no systematic examination is performed on their vertical structure and spatial-temporal variations. Additionally, the physical mechanisms for the formations and variations of the warm cores are open to debate. Therefore, based on the long-term ERA-interim reanalysis datasets, the present study aims to analyze the climatology of the warm cores at different vertical levels in detail and explore the possible physical mechanisms controlling the formation and variation of the warm cores around the TP.

The rest of the paper is organized as follows: The reanalysis datasets and methods used in this study are detailed in Sect. 2. In Sect. 3, the climatology of the warm cores is analyzed. We present the horizontal and vertical structures of the climatological warm cores and distinguish the different warm cores at the upper and lower levels around the TP. The seasonal variations of these two types of warm cores are also included in this section. The relevant possible mechanisms of the warm cores at the upper and lower levels are examined respectively in Sect. 4. Finally, summary and discussion are given in Sect. 5. 


\section{Data and methodology}

\subsection{Data}

The data used in this study include the following sources:

(1) Atmospheric circulation data are derived from European Centre for Medium-Range Weather Forecasts (ECMWF) interim reanalysis datasets (ERA-interim, Dee et al. 2011), which are available from https://apps. ecmwf.int/datasets/data/interim-full-daily/. Variables include temperature, wind (with the $\mathrm{u}$ and $\mathrm{v}$ components), vertical velocity and geopotential height at 27 pressure levels from 1000 to $100 \mathrm{hPa}$, with a spatial resolution of $1^{\circ} \times 1^{\circ}$. Data with a higher resolution of $0.5^{\circ} \times 0.5^{\circ}$ are used within the TP domain. Temporal resolution of the dataset is 6-h from January 1, 1979 to December 31, 2018. Gridded surface heat flux and radiation flux over the TP are also extracted from ERAinterim with a spatial resolution of $0.5^{\circ} \times 0.5^{\circ}$. In this study, upward is defined positive in the variables of surface net thermal radiation, surface sensible heat flux and surface latent heat flux, and downward is positive in the surface net solar radiation.

The reliability of ERA-interim dataset has been verified by previous studies (Wang and Zeng 2012; Bao and Zhang 2013), which ranked this dataset among the best reanalysis datasets in terms of spatio-temporal variations of air temperature over the TP. Here we conducted further data validation based on two newly-acquired observational datasets from the Chinese Meteorological Administration (CMA) with longer time span: (a) monthly surface temperature in China in $0.5^{\circ} \times 0.5^{\circ}$ grids (V2.0) (1979-2018) (http://data.cma.cn/data/ cdcdetail/dataCode/SURF_CLI_CHN_TEM_MON_ GRID_0.5.html) and (b) monthly upper air observations at specific layers in China (1980-2014) (http:// data.cma.cn/data/cdcdetail/dataCode/UPAR_WEA_ CHN_STL_MON.html). In March-June, observed surface air temperature pattern with "northwestern cold-southeastern warm" can be well reproduced in the ERA-interim dataset (Fig. S1a, b), with a correlation coefficient of 0.95 for the TP regional averaged surface temperature interannual variations. At tropospheric levels over the TP, the climatological vertical profile (Fig. S1c) and time series (Fig. S1 d) of air temperatures from the nine radiosonde mean show great consistency with the corresponding regional $\left(91-103^{\circ} \mathrm{E}, 29-37^{\circ} \mathrm{N}\right)$ mean of ERA-interim. The correlation coefficients of interannual variations of regional averaged air temperature between observations and ERA-interim are 0.97, 0.96, 0.92, 0.90 at $500 \mathrm{hPa}, 400 \mathrm{hPa}, 300 \mathrm{hPa}, 200 \mathrm{hPa}$, respectively. Therefore, ERA-interim can well capture the horizontal and vertical distributions, and the interannual variations of temperature over the TP, and it is suitable and credible to use this dataset to study the climatology of the warm cores over the TP.

The hourly temperature at 27 pressure levels is obtained from ERA-5 dataset (https://cds.climate. copernicus.eu/cdsapp\#!/dataset/reanalysis-era5-press ure-levels?tab=overview/; Hersbach and Dee 2016) to explore the vertical phase relationship of temperature on different vertical levels over the TP. This dataset is the latest and fifth generation of European reanalysis produced by the ECMWF, and has a spatial resolution of $0.5^{\circ} \times 0.5^{\circ}$.

(2) Monthly-mean outgoing longwave radiation (OLR) data (http://www.esrl.noaa.gov/psd/data/gridded/data. ncep.reanalysis.html; Liebmann and Smith 1996) for 1979-2018 is obtained from National Ocean and Atmosphere Administration (NOAA) at a spatial resolution of $2.5^{\circ} \times 2.5^{\circ}$.

\subsection{Methodology}

\subsubsection{Definition of the warm cores}

The monsoon system exhibits a strong seasonal evolution and is often featured by a zonally asymmetric circulation (due to large land-ocean thermal contrast and topographical distribution). Whereas the midlatitude circulation has a zonally symmetric component, to aid in analyzing the zonally asymmetric component and its seasonal variation, the symmetric component is often removed from the original atmospheric variable. This method is commonly applied in the study of monsoonal circulation. For instance, Kawamura et al. (2002) extracted the zonal deviations of wind and temperature, and showed them to be useful for understanding the Australian monsoon circulation. Furthermore, Minoura et al. (2003), Prasad and Hayashi (2005) applied this method to explain the onset and withdrawal of the Indian summer monsoon. Using the zonal deviation field of the vertically averaged temperature (500-200 hPa), Zhao et al. (2007) identified a zonal teleconnection pattern, the Asian-Pacific Oscillation, over the extratropical Asian-Pacific region. Yanai et al. (1992) also calculated the deviation from the regional mean field to stress the heating effect of the TP. Therefore, in our study, the four-dimensional zonal temperature deviation $\left(T^{\prime}\right)$ for each grid at each level is adopted to define the warm center. It is formulated as

$T^{\prime}(x, y, z, t)=T(x, y, z, t)-\bar{T}(y, z, t)$

where $T$ is the original four-dimensional temperature field, and $\bar{T}$ is the zonal mean of $T$. 
From the climatological distributions of the tropospheric $T^{\prime}$ and $T$ at each level in boreal summer (not shown), the positions of $T^{\prime}$ maximum coincide consistently with the temperature warm centers. Therefore, tropospheric warm cores can be well captured in the $T^{\prime}$ fields. Notably, by using $T^{\prime}$ instead of the original $T$, it overcomes the defect that warm cores at different levels are hard to compare directly.

Following the definition of westerly jet core (Ren et al. 2010), warm cores at each tropospheric level are determined using an event-based method (Koch et al. 2006). Based on the study of Rowson and Colucci (1992), the horizontal extent of the surface thermally driven systems is typically on a spatial scale of $500-1500 \mathrm{~km}$ (1000 km in average). Thus, the warm cores with a horizontal scale smaller than $1000 \mathrm{~km}$ are excluded as they are mostly induced by the local sub-synoptic and mesoscale systems, which are beyond the scope of our research. A warm core is identified, and its corresponding latitude and longitude positions are recognized if (1) $T^{\prime}$ is equal to or greater than $3 \mathrm{~K}$ and (2) $T^{\prime}$ is the local maximum of the surrounding 80 grid points (in a region with the horizontal scale of approximately $1000 \mathrm{~km} \times 1000 \mathrm{~km}$ ). The procedure is repeated to process all the 6-hourly data that covers the entire study period of 1979-2018 and the total number of warm core occurrence is counted for each grid point at each vertical level (600-100 hPa). Meanwhile, the corresponding $T^{\prime}$ value of the identified warm core is defined as the warm core intensity. According to the definition, more than one warm core center may appear over the plateau at a particular time due to the massive area of the TP (approximately 2.5 million square kilometers).

The warm core occurrence frequency (WCOF) during a time period is defined as the ratio between the warm core occurrence number and the total number of time intervals (expressed by percentage). The warm core intensity is defined as the averaged intensity of the total warm cores during that time period.

\subsubsection{Heat budget balance}

Based on the first law of thermodynamics, the local air temperature change with time can be expressed by three components as follows (Chen and Baker 1986),

$\frac{\partial T}{\partial t}=-V \cdot \nabla T-\omega\left(\frac{p}{p_{s}}\right)^{R / C_{p}} \frac{\partial \theta}{\partial p}+\frac{\dot{Q}}{C_{p}}$

where $-V \bullet \nabla T$ is horizontal temperature advection (HTAD); $-\omega\left(\frac{p}{p_{s}}\right)^{R / C_{p}} \frac{\partial \theta}{\partial p}$ is adiabatic heating $(\mathrm{ADH}) ; \frac{\dot{Q}}{C_{p}}$ is diabatic heating $(\mathrm{DH})$, with $\mathrm{V}$ the horizontal wind vector, $\mathrm{p}$ the pressure, $\mathrm{p}_{\mathrm{s}}$ the surface pressure, $\mathrm{R}$ the gas constant, $\mathrm{T}$ the air temperature, $\omega$ the vertical wind speed, $\theta$ the potential temperature, $\mathrm{Q}$ the heat content, and $\mathrm{C}_{\mathrm{p}}$ the specific heat capacity at constant pressure. Note that the local change in zonal-mean temperature with time $\frac{\partial \bar{T}}{\partial \mathrm{t}}$ is insignificant compared to $\frac{\partial T}{\partial t}$ and is negligible. In this case $\frac{\partial T}{\partial \mathrm{t}} \approx \frac{\partial T^{\prime}}{\partial \mathrm{t}}$, the local change in $T^{\prime}$ can also be explained by the three components in Eq. (2). The term DH $\left(\frac{\dot{Q}}{C_{p}}\right)$ is calculated using residual budget analyses (Yanai et al. 1973).

\subsubsection{Surface heat source}

According to Ye and Gao (1979), the surface heat source (SHS) over the TP is defined as follows,

$S H S=S H+L H+L R$

where SH is the surface sensible heat flux, LH is the surface latent heat from evaporation and LR is the effective radiation from the surface. Positive SHS denotes that heat is transferred upward from the underlying surface to the atmosphere.

\section{Climatology of the tropospheric warm cores over the TP and its vicinity}

\subsection{Horizontal and vertical distribution}

Before examining the climatology of the warm cores, it is necessary to present the climatological distribution of $T^{\prime}$. From the annual-mean perspective, the high values of $T^{\prime}$ around the TP at all levels manifest that the TP and its adjacent areas are the relatively warmer regions than other areas at the same latitude (Fig. 1). The maxima of $T^{\prime}$ occur over the $\mathrm{TP}$ at $550 \mathrm{hPa}$ and $200 \mathrm{hPa}$, which are referred to as the warm cores that we will discuss in the following sections. The warm core at $550 \mathrm{hPa}$ is situated on the main body of the TP, while warm core at $200 \mathrm{hPa}$ is located on the southern TP. The magnitudes of these warm centers at both levels are around 3-4 K. At tropospheric levels above $400 \mathrm{hPa}$, $T^{\prime}$ is characterized by high values in a zonal band between $20^{\circ} \mathrm{N}$ and $30^{\circ} \mathrm{N}$ over the Asian and western Pacific sector.

Using the method described in Sect. 2.2.1, we examined the warm core occurrence frequency (WCOF) at four tropospheric levels (Fig. 2). At $550 \mathrm{hPa}$, the near surface of the $\mathrm{TP}$, the warm cores mainly appear within the interior of the $\mathrm{TP}$ (concentrated in $80-100^{\circ} \mathrm{E}, 28-38^{\circ} \mathrm{N}$ ) and are characterized by regional patches with high frequency occurrences. The active region is in the central and western TP, with a high WCOF region greater than $1 \%$ (Fig. 2a). The mid-west TP has the highest topography and it is also the primary source for the development of plateau vortex (Qian et al. 1984; Feng et al. 2014). Warm cores at $550 \mathrm{hPa}$ also scatter 

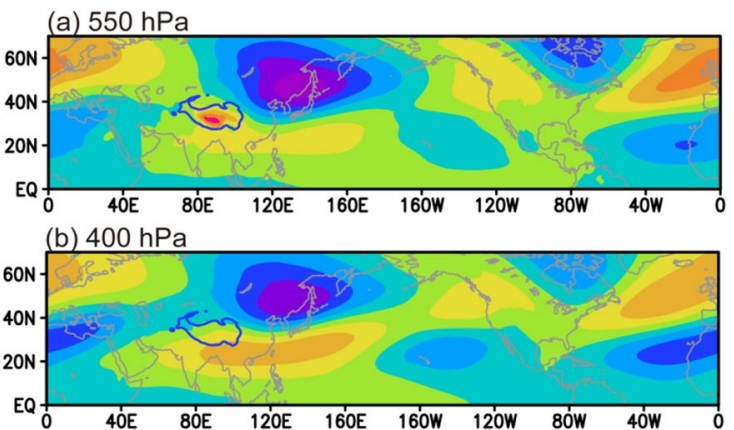

(c) $300 \mathrm{hPa}$
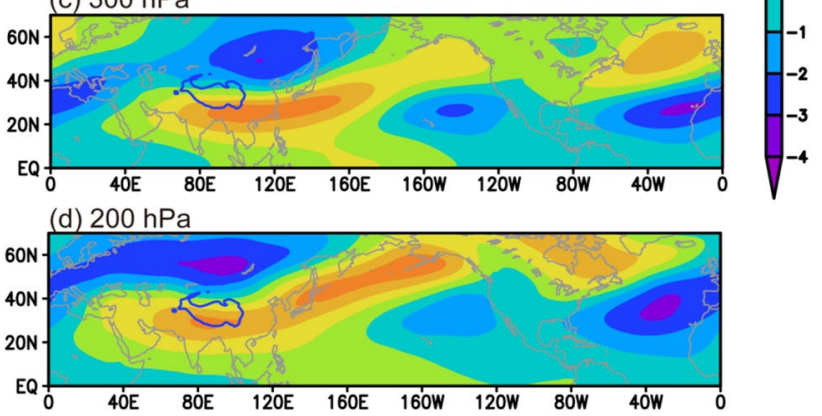

Fig. 1 Distributions of climatological annual-mean $T^{\prime}$ at different tropospheric levels (Units: K). a $550 \mathrm{hPa}$, b $400 \mathrm{hPa}$, c $300 \mathrm{hPa}$, and d $200 \mathrm{hPa}$. The blue solid curves denote topographic contour line of $3000 \mathrm{~m}$, representing the TP domain

in the northern periphery of the TP, the western YunnanGuizhou Plateau, and South Afghanistan-West Pakistan, but their occurrences are less frequent and are largely associated with the local topography-producing thermal lows (Bollasina and Nigam 2011; Smith and Spengler 2011). At the levels higher than $400 \mathrm{hPa}$, the spatial distribution of WCOF is featured less by regional patches, but displays a zonally elongated band pattern, which is consistent with the annualmean distribution of $T^{\prime}$ in Fig. 1. Warm cores at $200 \mathrm{hPa}$ and $300 \mathrm{hPa}$ are concentrated around the central and southern TP (concentrated in $60-110^{\circ} \mathrm{E}, 25-35^{\circ} \mathrm{N}$ ).

The vertical distributions of WCOF are depicted in Fig. 3. As shown in the latitude-height cross section in Fig. 3a, there are two clear centers with high WCOF over the TP and its adjacent areas, corresponding to the upper-level warm cores (ULWCs) and lower-level warm cores (LLWCs). The LLWCs are located in the main body of the TP $\left(30-40^{\circ} \mathrm{N}\right)$ and are vertically confined in a shallow layer from the surface to approximately $450 \mathrm{hPa}$. There is a sharp WCOF vertical gradient below $450 \mathrm{hPa}$, with WCOF maximum situated at the surface. The ULWCs appear aloft within $200-400 \mathrm{hPa}$ and are located in $25-35^{\circ} \mathrm{N}$ with a $5^{\circ}$ southward shift with respect to the LLWCs. There is a clear vertical disconnection in $\mathrm{WCOF}$ at $450-400 \mathrm{hPa}$, representing the transitional zone separating the two types of warm cores. Similarly, vertical distribution of WCOF in the longitude-height cross section (Fig. 3b) shows a layer of high occurrence from the surface to $450 \mathrm{hPa}$ within the TP domain $\left(80-100^{\circ} \mathrm{E}\right)$ with maxima at the surface. The ULWCs are dispersed within a zonal band at $250-150 \mathrm{hPa}$. Another important feature is that the upper-level WCOF outside the TP domain in either east side $\left(105-120^{\circ} \mathrm{E}\right)$ or west side $\left(60-80^{\circ} \mathrm{E}\right)$ shows no significant
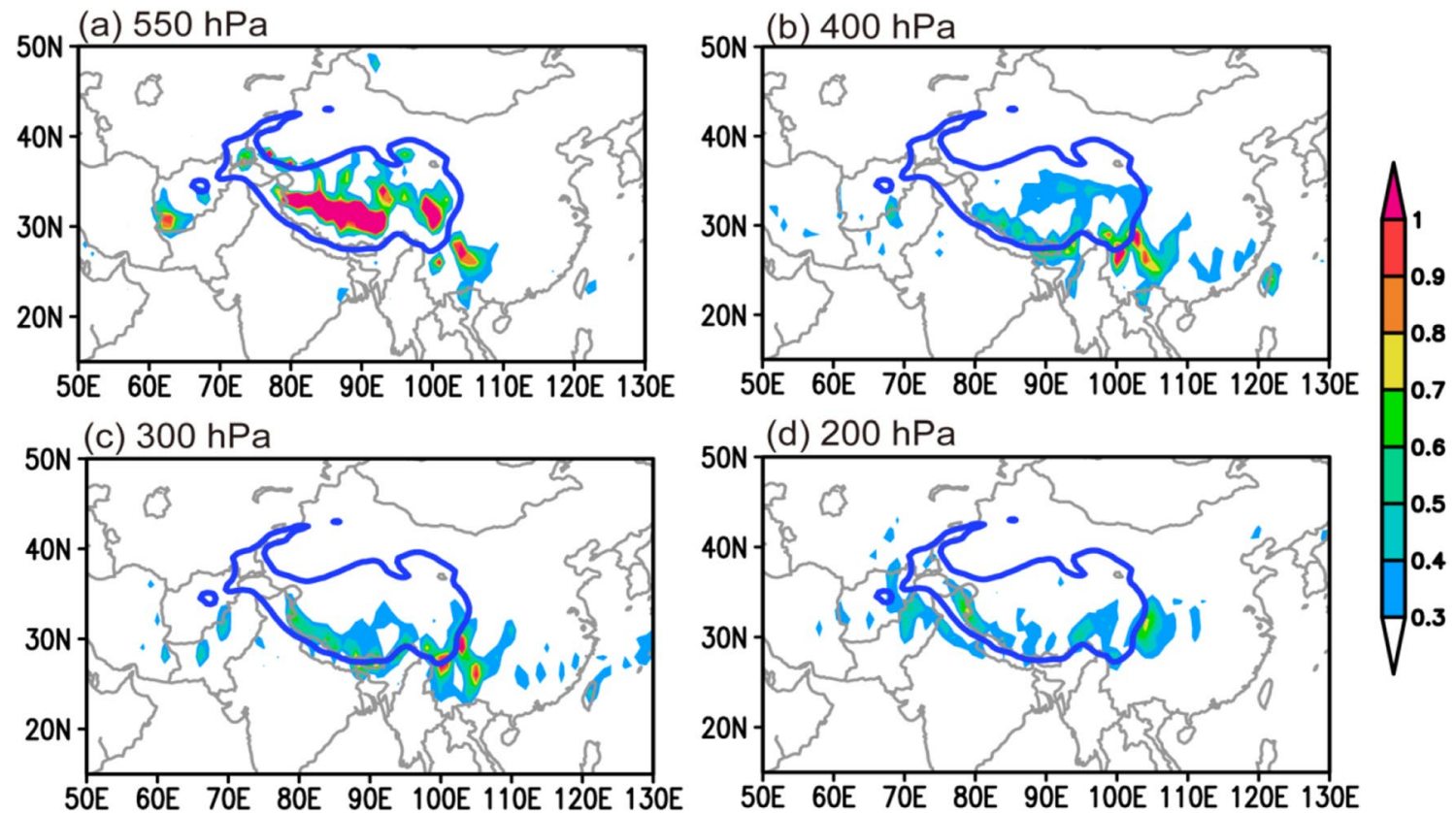

Fig. 2 Spatial distributions of the climatological-mean annual warm core occurrence frequency (WCOF) at different tropospheric levels (Units: $\%$ ). a $550 \mathrm{hPa}, \mathbf{b} 400 \mathrm{hPa}, \mathbf{c} 300 \mathrm{hPa}$, and $\mathbf{d} 200 \mathrm{hPa}$. The blue solid curves represent the TP domain 

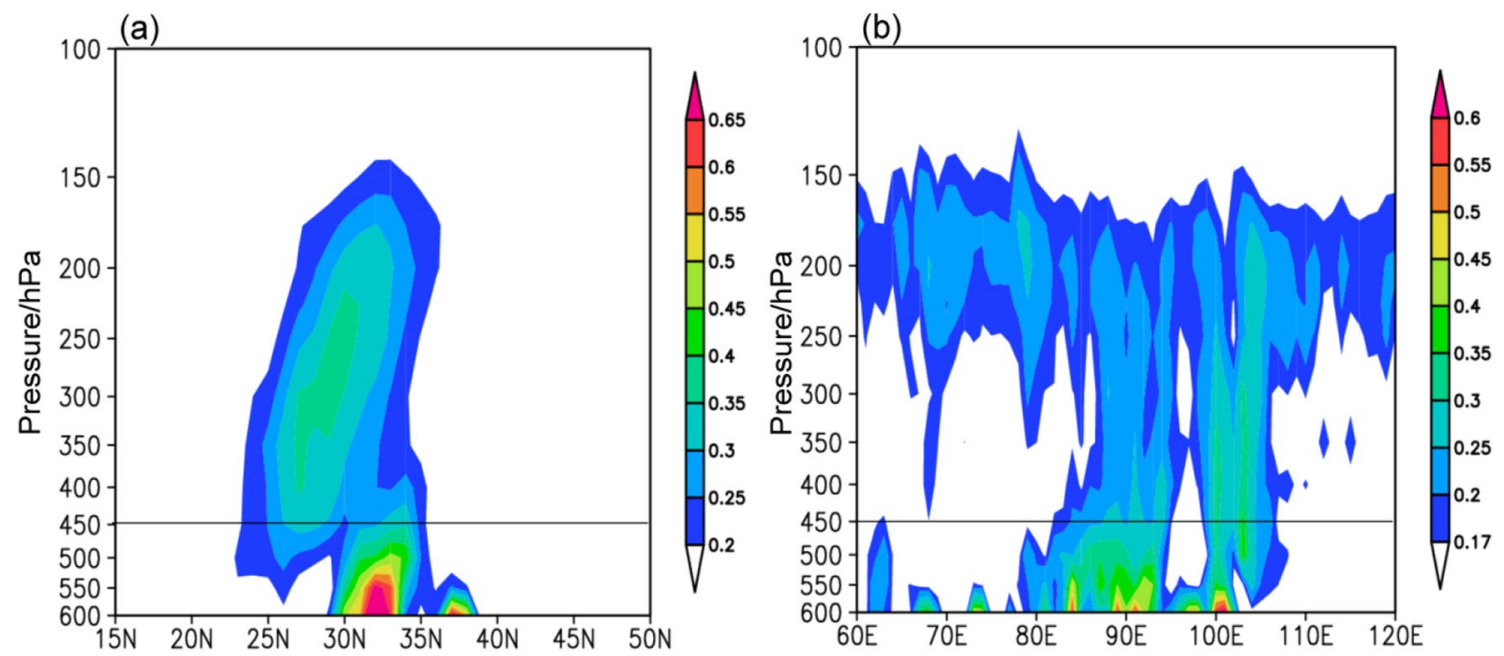

Fig. 3 Vertical distributions of the climatological-mean annual WCOF at the latitude-height (a, along $\left.70-110^{\circ} \mathrm{E}\right)$ and longitude-height $(\mathbf{b}$, along $25-45^{\circ} \mathrm{N}$ ) cross sections

differences from that within the TP domain, whereas the lower-level WCOF is considerably larger than the non-elevated flanks. These evident structural differences of the two types of warm cores are indicative of the possibility that the occurrence of warm cores at lower level may have great relevance to the existence of the TP but those at upper levels may not.

The average thickness of atmospheric planetary boundary layer over the TP is 2-3 km (Ye and Gao 1979), and the synoptic systems generated within the TP, such as summer heat low (Gao et al. 1981) and the TP vortex (Qian et al. 1984), may reach the level of $400 \mathrm{hPa}$. The top height of the LLWCs is consistent with the documented topographyrelated boundary layer heights, which suggests that the synoptic weather systems within the TP may be the primary drivers for genesis and development of LLWCs.

\subsection{Annual cycle and seasonal variation}

The warm cores exhibit pronounced seasonal variations which can be described by seasonal evolutions of both the magnitude and position of the high WCOF. As presented in Fig. 4, the distributions of WCOF show large seasonal variations with different characteristics at different levels. At the lower level $(550 \mathrm{hPa})$ over the TP, the warm cores occur most frequently in boreal summer (JJA) and are suppressed in winter (DJF). During spring (MAM), summer (JJA), and autumn (SON) seasons, the high WCOF shows almost fixed locations within the interior area of the plateau and centered at approximately $90^{\circ} \mathrm{E}, 30^{\circ} \mathrm{N}$ in the central TP. In DJF, the whole plateau is mainly dominated by the cold air, so $T^{\prime}$ is positive only in the mid-eastern TP and northwestern periphery, with scattered centers of warm core occurrences.
The WCOF is explosively enhanced at the central TP during spring, peaks in summer, and reduces gradually during autumn. The seasonal evolution of WCOF at the lower level is synchronous with the insolation evolution, implying the dominant impact of surface-heating process. The WCOF centers in summer and autumn exhibit a modest westward displacement. The spatial patterns in spring and summer are consistent with previous studies by He et al. (1987) and Yanai et al. (1992), but the lower-level warm cores defined in our study appear a little earlier, and this is mainly because we choose $550 \mathrm{hPa}$ level (closer to the ground) $T^{\prime}$ instead of $500 \mathrm{hPa}$ temperature to calculate the lower-level warm cores.

In contrast to a strong seasonal cycle of WCOF at lower level, the warm cores around the TP at $200 \mathrm{hPa}$ exhibit different seasonal features. These upper level warm cores exist throughout the entire year, and are featured by a zonally elongated band stretching across the extratropical Asia. In the cold seasons (DJF and MAM), the bands of warm cores are situated around the southern plateau, while in the warm seasons (JJA and SON), they become wider with a poleward extension and displacement. The climatological $T^{\prime}$ in DJF shows that the wintertime warm center is pronounced in an area east of the TP, but in the event-based calculation, there are also scattered warm core occurrences on the southern periphery of the $\mathrm{TP}\left(30^{\circ} \mathrm{N}\right)$. The spatial distribution of WCOF in JJA shows the spread to a larger region compared to other seasons, and the maxima exhibit a notable poleward and westward shift from the southern TP to the Pamirs plateau. It should be noted that, if we focus on the warm core occurrences only within the TP domain, they are most frequently observed in MAM instead of JJA, since the high WCOF already moved out of the main body of the TP in boreal summer. 

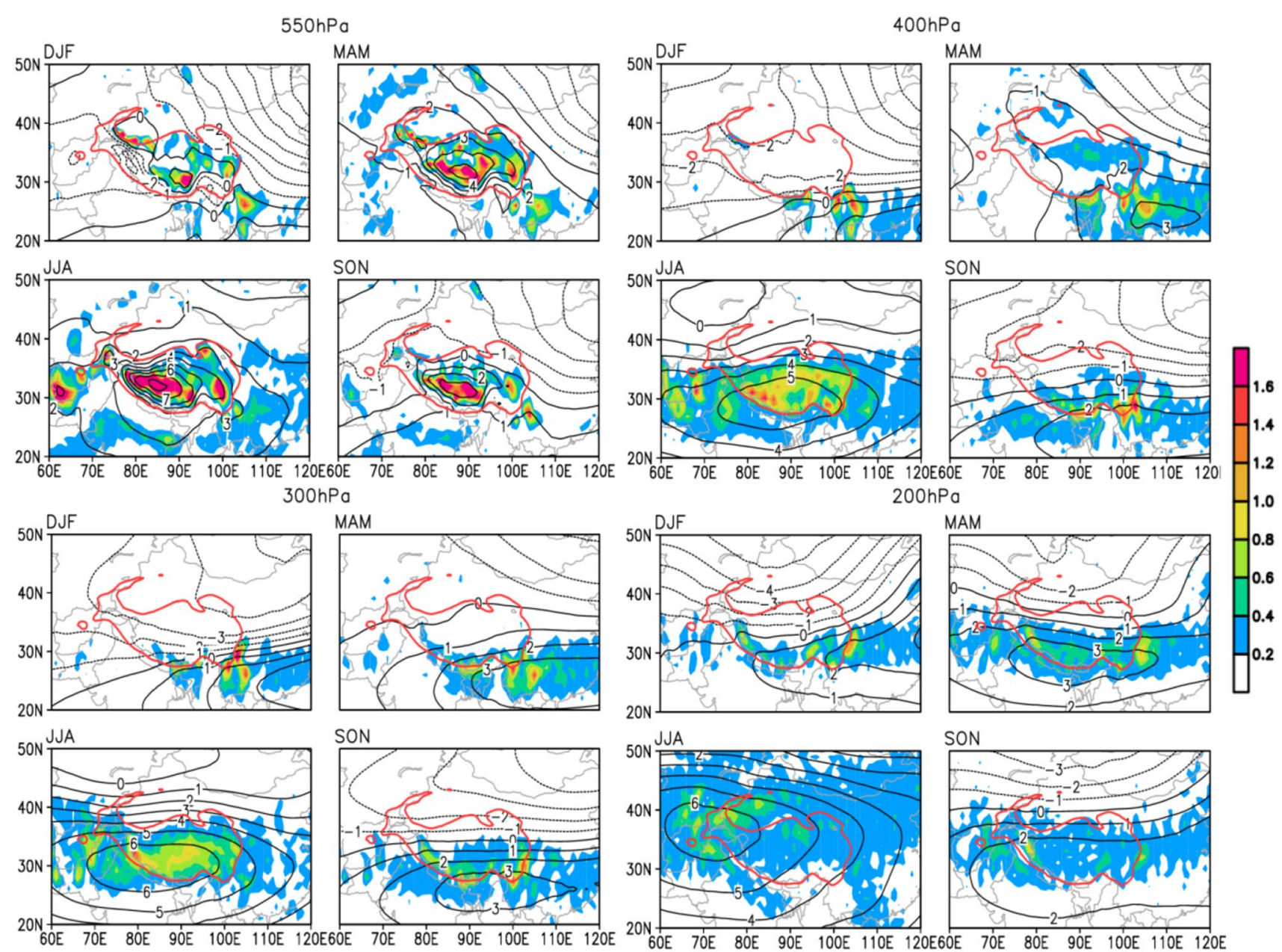

Fig. 4 Distributions of the climatological-mean four-seasonal WCOF (colored, units: \%) and $T^{\prime}$ (contour, units: K) at four tropospheric levels (the red solid curves represent the TP domain)

Seasonal evolutions of warm cores at $300 \mathrm{hPa}$ and $400 \mathrm{hPa}$ are more or less similar to those at $200 \mathrm{hPa}$. Warm cores are frequently observed in the southern periphery of the TP in DJF and MAM, whereas the occurrence within the TP domain is sporadic (less than $0.2 \%$ ). In boreal summer, the whole TP shows a drastic increase in WCOF, implying a sudden genesis and development of warm cores. The high WCOF retreats to the southern periphery of the TP in SON.

In the present study, $550 \mathrm{hPa}(200 \mathrm{hPa})$ is selected to represent the lower (upper) level over the TP. In order to demonstrate monthly variation of warm cores with high WCOF, firstly, we select all grids with monthly WCOF larger than $2 \%$ during March to October at $550 \mathrm{hPa}$ and $200 \mathrm{hPa}$ respectively. We further obtain latitudes and longitudes of selected grids within the area of $60-110^{\circ} \mathrm{E}, 20-45^{\circ} \mathrm{N}$ (around the TP). Only the months from March to October are chosen for calculation because the warm cores are strongly suppressed in winter. As shown in Fig. 5a, b, the LLWCs show generally weak seasonal variations in their zonal and meridional positions. Especially on the meridional location, the median latitudes in each month are nearly fixed at $32^{\circ} \mathrm{N}$. For the zonal location, there is a weak westward shift in median longitudes from spring to summer (shifting by $6^{\circ}$ ). At the upper level, the monthly locations of warm cores show larger seasonal variations (Figs. 5c, d) compared with LLWCs. The positions of ULWCs show a significant northwest shift in summer with large changes for the median longitudes (westward shifting by $12^{\circ}$ ) and latitudes (northward shifting by $7^{\circ}$ ) and these changes are much larger than LLWCs.

The LLWCs and ULWCs are decoupled vertically and are represented as two groups of independent centers in winter, spring and autumn, but they become connected vertically and form one center with a deep vertical structure in summer (Fig. 6). It is clear that the regional LLWCs are formed in February with a reversed sign (from negative in January to positive in February) in $T^{\prime}$ and they are confined to a shallow layer below $500 \mathrm{hPa}$ over the TP, probably driven by the weak surface heating, while the ULWCs are observed within 

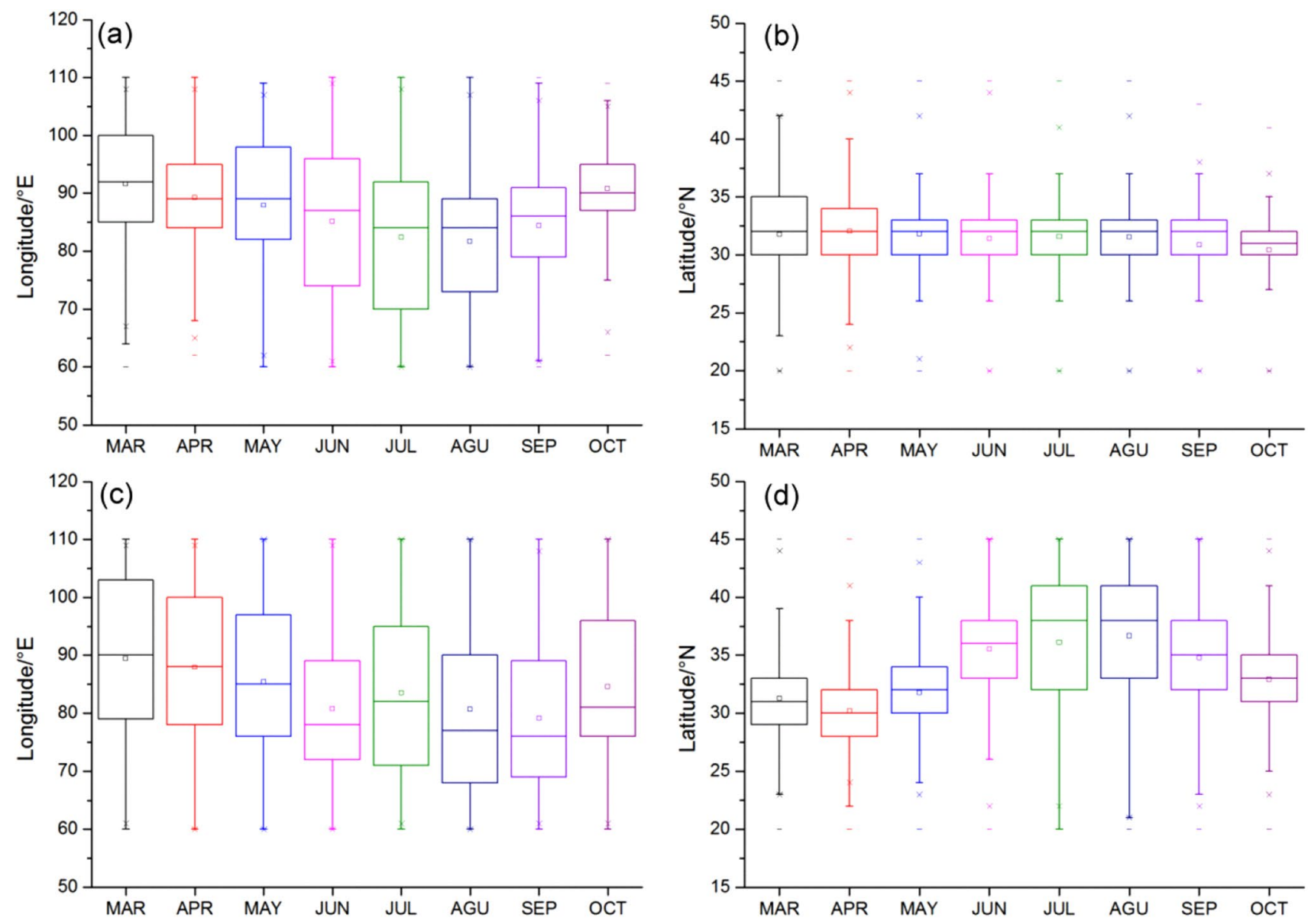

Fig. 5 Boxplots of latitudes and longitudes with high monthly WCOF at $550 \mathrm{hPa}(\mathbf{a}, \mathbf{b})$ and $200 \mathrm{hPa}(\mathbf{c}, \mathbf{d})$ around the TP. The thin and short lines at the top and bottom are the maximums and minimums. The bottom and top of the rectangles refer to the 25 th and 75 th percentiles of the data. The lines through the rectangles represent the medians,

and the upper and lower stems represent the boundaries of nonoutlier maximums and minimums (1.5 times the interquartile range away from 25 and 75 th percentiles). The cross symbols represent the outliers. The small open boxes represent the mean values

$150-400 \mathrm{hPa}$ at $30^{\circ} \mathrm{N}$. With seasonal advance, the LLWCs tend to amplify and extend upward in warmer months in response to the seasonal deepening of boundary layer (Ye and Gao 1979) while the ULWCs amplify and extend downward with $T^{\prime}$ center being prolonged vertically in the whole troposphere. During this transition period from February to June, the border separating the two types of warm cores is clearly observed at 400-450 hPa. In July and August, with the frequent establishment of the warm cores at $300-400 \mathrm{hPa}$ over the TP, the upper and lower level warm cores merge into a single one with a deep vertical structure. From September to wintertime, the two types of warm cores show reversed variations as those from February to June. Both the LLWCs and ULWCs become weak and shrink vertically, with decoupling becoming visible again from October.

The WCOF and warm core intensity are calculated specially within the TP interior above $3,000 \mathrm{~m}$ and are illustrated in Fig. 7. The ULWCs occur most frequently and

the intensity attains its maxima during March to June. At $200 \mathrm{hPa}$, the major peak of WCOF appears in late May with strong intensity, and a sub-peak WCOF occurs in October with much weak intensity. The relatively less occurrence in summer is due to the fact that the ULWCs are mostly generated around the Pamirs Plateau during this period, instead of over the main body of the TP (Fig. 4). The LLWCs develop rapidly from March to June with both frequency and intensity reaching the maxima in summer. It should be noted that March to June is a critical period as the warm cores at both lower and upper levels grow at the fastest rate. Additionally, during this period, the warm cores at lower and upper levels are well separated vertically. Therefore, studies shall be conducted with respect to the formation and development of the two vertically separated warm cores and special consideration shall be given to the March to June period.

If we set 3.5 times per day of WCOF as the threshold of active phase for tropospheric warm core occurrence, 

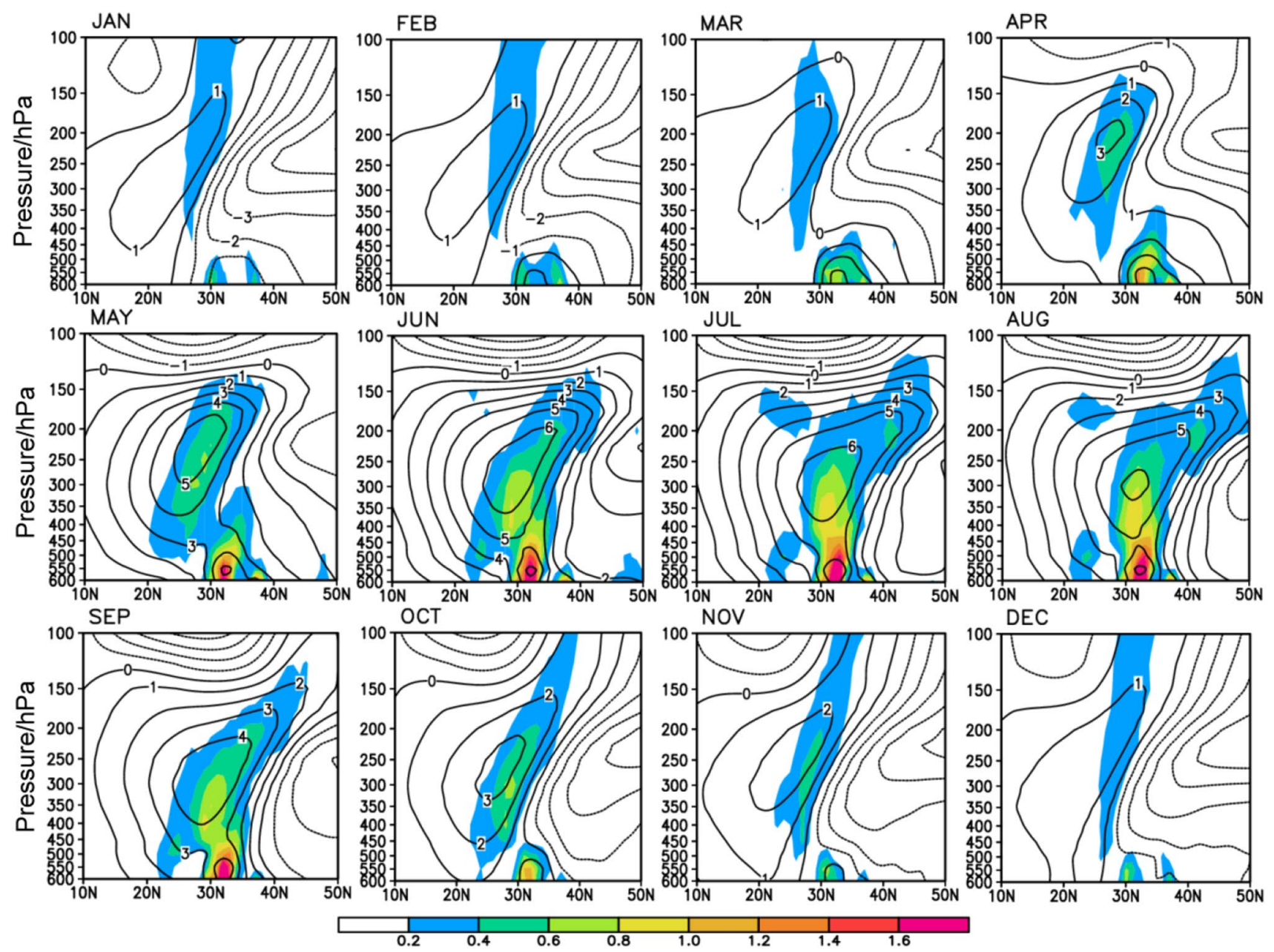

Fig. 6 Latitude-height (along $80-100^{\circ} \mathrm{E}$ ) cross sections of climatological-mean monthly WCOF (colored, units: \%) and $T^{\prime}$ (contour, units: K) around the TP

the active phase starts approximately from early March and ends in late October. Warm cores at upper and lower levels enter the active phase and their rapid intensification starts earlier than the middle level (Figs. 7c, d). The $550 \mathrm{hPa}$ warm cores are the earliest to enter the active phase (in middle February), followed by the warm cores at $200 \mathrm{hPa}$ (in early March), and the $400 \mathrm{hPa}$ warm cores are the latest to enter the active phase (in middle May). The $200 \mathrm{hPa}$ WCOF and intensity (Figs. 7c, d) reach a peak in late May, leading the $550 \mathrm{hPa}$ and $400 \mathrm{hPa}$ by approximately two months. The frequency and intensity of $200 \mathrm{hPa}$ warm cores stay higher than those of $400 \mathrm{hPa}$ warm cores before early June. The leading active phase and the leading peak intensity at $200 \mathrm{hPa}$ suggest that the genesis of the ULWCs may originate from other factors rather than the direct upward extension from the nearsurface within the TP.

\section{Physical mechanisms for the formations of the LLWCs and ULWCs over the TP}

In Sect. 3, we identified the coexistence of upper and lower level warm cores over the TP. These two types of warm cores differ significantly in their seasonal variations and active phases, which implies that physical mechanisms for their formations and variations might be also different. As mentioned above, March to June is a critical period for the rapid development of warm cores and therefore warrants a special consideration. The following analyses are all based on this period. During March to June, the intensities of warm cores at all levels are significantly depending on the temperature variations. The temperature and warm core intensity are positively correlated at each tropospheric level with correlation coefficients greater than 0.7 (passing the significance test at the $99.9 \%$ confidence level, not shown). That is to say, the warmer environment over the TP favors the warm core formation. In this section, different mechanisms leading to the 


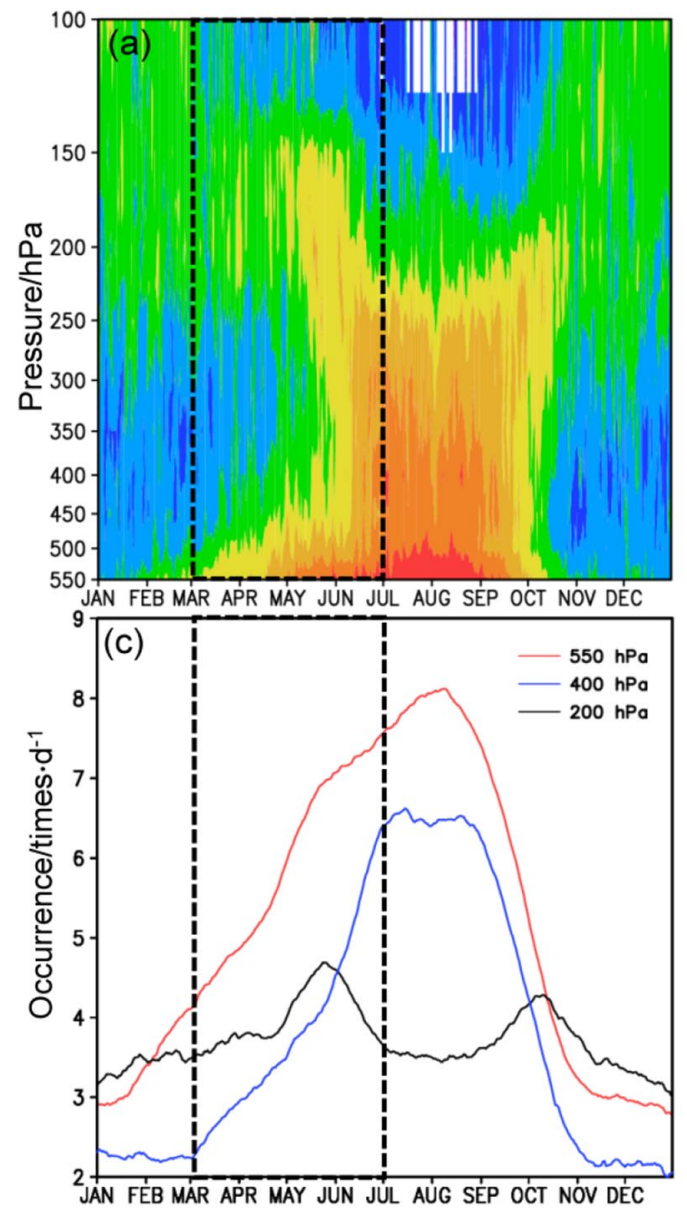

Fig. 7 a Time-height cross sections of climatological WCOF (Units: times day ${ }^{-1}$ ) within the TP domain (elevation higher than 3,000 m). b Same as (a), but for warm core intensity (Units: K). c Same as (a), but for three typical tropospheric levels: $550 \mathrm{hPa}, 400 \mathrm{hPa}$ and

LLWCs and ULWCs are demonstrated based on heat budget balance decomposition and regression analysis.

\subsection{Contribution of each component in heat balance}

According to heat budget balance equation in Sect. 2.2.2, the local change of temperature with time can be decomposed into three components: the diabatic heating term, the adiabatic heating term and the horizontal temperature advection term. The seasonal evolutions of the three heating components and $T^{\prime}$ are examined over the TP domain based on the climatological data and results are illustrated in Fig. 8.

Consistent with Fig. 7a, there are two vertically separated warm temperature cores before June and after October in the seasonal evolution of $T^{\prime}$ (Fig. 8a). Lower level warm temperatures develop at the surface in February-March and extend upward with seasonal advance, while upper warm temperatures exist all year around and
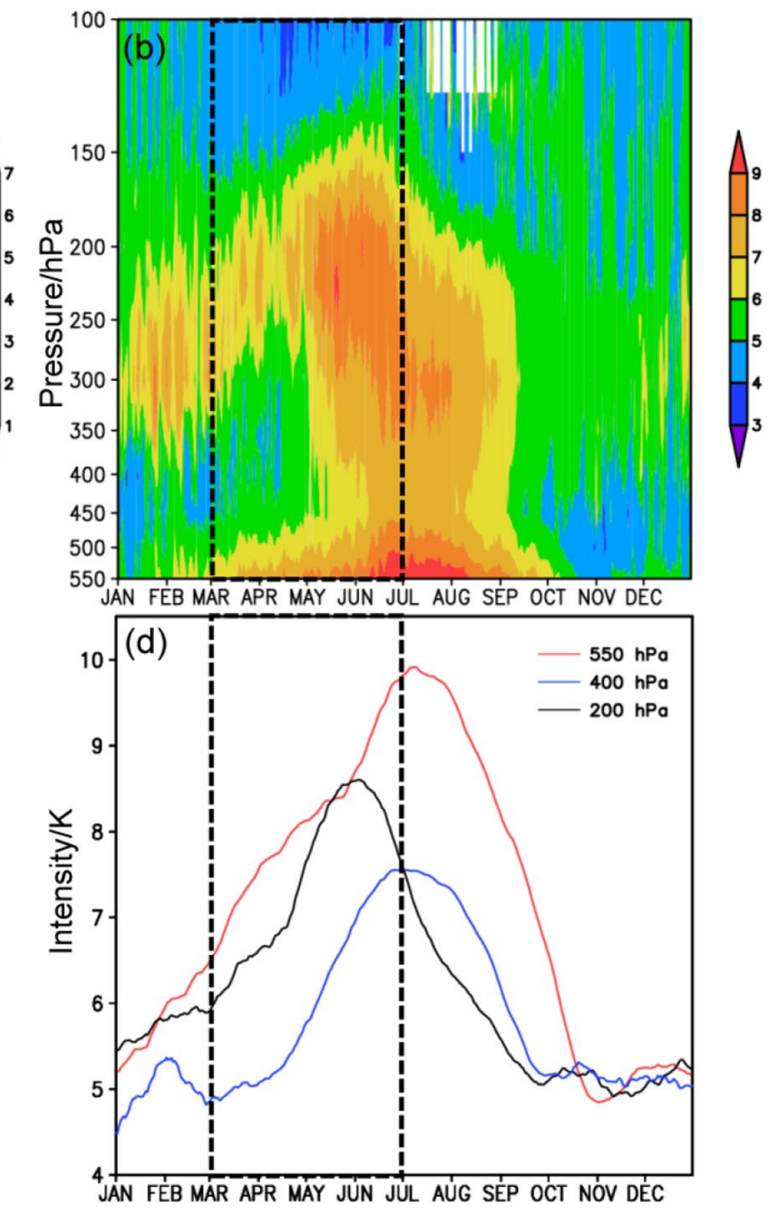

$200 \mathrm{hPa}$ (Units: times day ${ }^{-1}$ ). d Same as (c), but for warm core intensity (Units: K). A 31-day running mean has been applied on the original time series in (c) and (d) to filter out high frequency noise

extend downward from April. The seasonal evolution of diabatic heating (Fig. 8b) shows positive values starting in late winter at lower levels, but they are mainly confined to the layers lower than $300 \mathrm{hPa}$ during March to June and its seasonal evolution shows similar features as that of lower level warm temperatures. The time from diabatic cooling to diabatic warming is delayed with height at levels below $300 \mathrm{hPa}$, which also matches the delayed air warming with height. These evidences indicate that diabatic heating is responsible for the formation and variation of the lower level warm air temperatures. Significantly distinct from the lower layers, the upper-level temperature increases are dominated mainly by adiabatic heating and horizontal advection processes. Adiabatic heating contributes to the 400-150 hPa warming during cold months (from January to April, and from November to December). The horizontal warm advection contributes to the tropospheric warming above $300 \mathrm{hPa}$ during warm months (April to October) (Figs. 8c, d). 

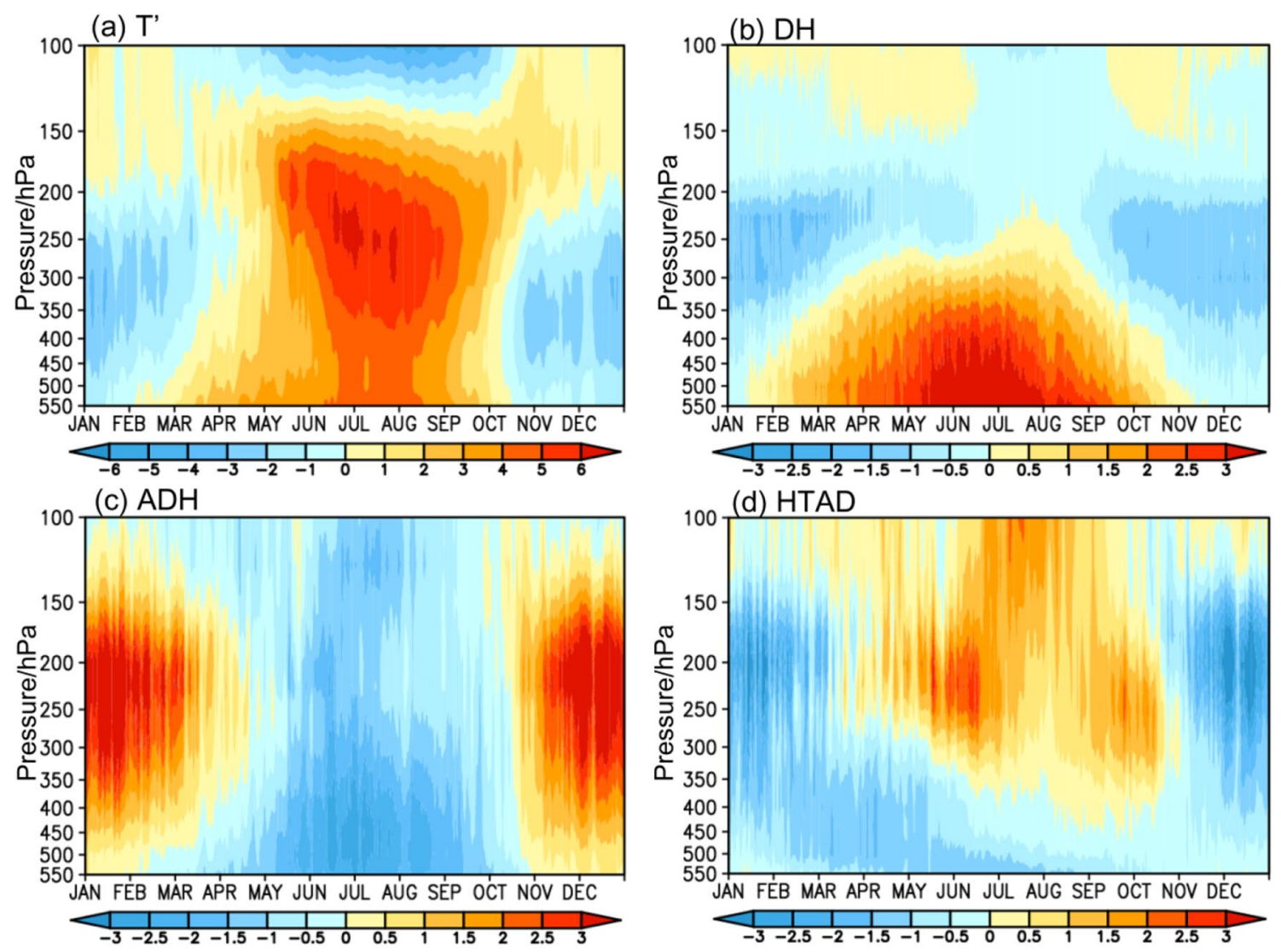

Fig. 8 Time-height cross sections of climatological T' (Units: K) and the heat budget terms (Units: K day-1) within the TP domain (elevation higher than $3000 \mathrm{~m}$ ). a T', b Diabatic heating (DH), c Adiabatic heating (ADH), and d Horizontal temperature advection (HTAD).

In order to discuss the heat budget balance in detail, we divide the period of March to June into two sub-periods (March to April, referred to as MA; May to June, referred to as $\mathrm{MJ}$ ) and spatial distributions of different heating terms during these two sub-periods in the upper and lower levels are illustrated in Fig. 9. At $550 \mathrm{hPa}$, high DH occurs over the entire TP, with the magnitude of DH in MJ larger than that in MA (Figs. 9b, d). Adiabatic cooling due to updraft and cold advection tend to damp the local warming, manifesting DH as a driver in lower-level warming.

At $200 \mathrm{hPa}, \mathrm{DH}$ is negative in both MA (Fig. 9a) and MJ (Fig. 9c), which suggests the upper level is dominated by diabatic cooling (mainly the radiative cooling). In MA, horizontal advection within the whole TP interior is weak due to the compensation of western warming and eastern cooling. It should be noted that, in MA, an adiabatic warm band (Fig. 9e) occurs in the central and southern TP and to the southwest $\mathrm{TP}\left(60-100^{\circ} \mathrm{E}, 25-35^{\circ} \mathrm{N}\right)$; this zonal band of adiabatic heating corresponds well with the upper-level zonal band of WCOF in Fig. 4. In MJ, strong adiabatic heating region moves to the western flank of the TP (Fig. 9g), and the downstream TP is warmed by horizontal advection associated with the strong westerly (Fig. 9k).
The vertical profiles of the heat budget terms over the TP domain in MA and MJ are analyzed in Fig. 10. The formation of the LLWCs is mainly attributed to the surface heating, as the diabatic heating below $450 \mathrm{hPa}$ dominates the entire TP domain and overwhelms the adiabatic cooling and cold advection. The DH profiles in both MA and MJ show uniform maxima below $500 \mathrm{hPa}$ and a rapid decrease upward above $500 \mathrm{hPa}$. This suggests that the $\mathrm{DH}$ at the lower troposphere is mainly contributed by the turbulent sensible heat flux and long-wave radiation due to the fact that sensible heat flux and long-wave radiation are the strongest at surface level. Seto et al. (2013) investigated the heating process in 2008 and 2009 based on radiosonde and mesoscale model data, and proposed that the sensible heating should be responsible for warming of the lower atmosphere (below $450 \mathrm{hPa}$ ) over the TP. At upper levels (200-300 hPa), the ADH overwhelms the diabatic cooling in MA (Fig. 10a), while the HTAD overwhelms the adiabatic and diabatic cooling in MJ (Fig. 10b). Therefore, the ULWCs are generated due to adiabatic heating in MA and warm advection in MJ, which is in contrast to the formation of the LLWCs.

The above analyses show contrasting physical processes for the formations of LLWCs and ULWCs over the TP with 
(a) $\mathrm{DH} \mathrm{MA} / 200 \mathrm{hPa}$

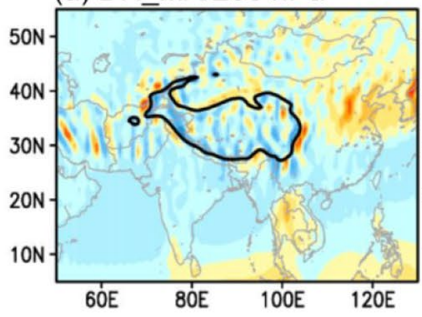

(e) $\mathrm{ADH} \_\mathrm{MA} / 200 \mathrm{hPa}$

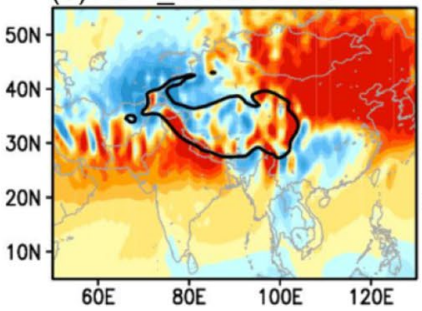

(i) HTAD_MA/200 hPa

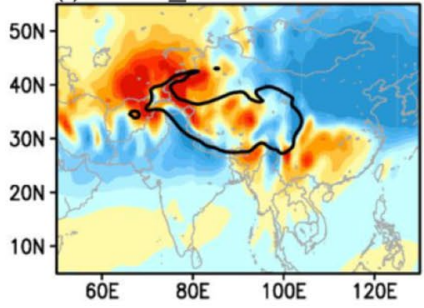

(b) DH_MA/550 hPa

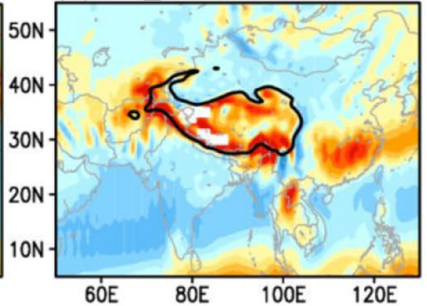

(f) $\mathrm{ADH} \_\mathrm{MA} / 550 \mathrm{hPa}$

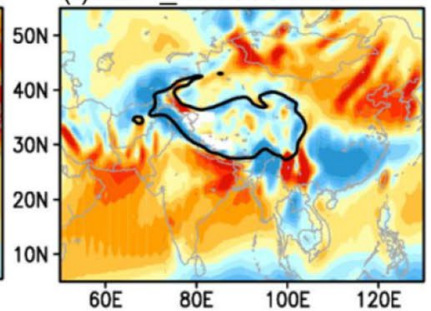

(j) HTAD_MA $/ 550 \mathrm{hPa}$

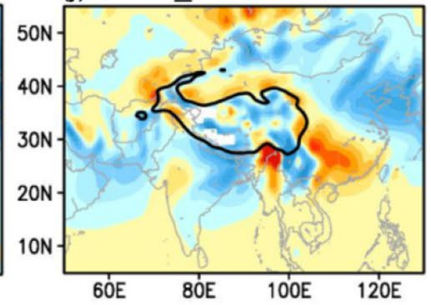

(c) $\mathrm{DH} \mathrm{MJ} / 200 \mathrm{hPa}$

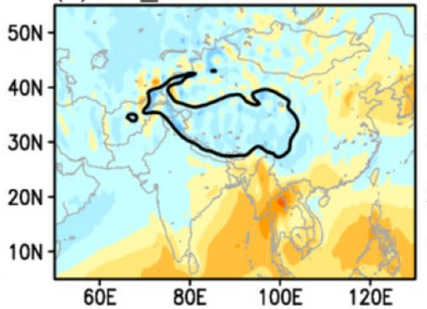

(g) $\mathrm{ADH} \mathrm{MJ} / 200 \mathrm{hPa}$

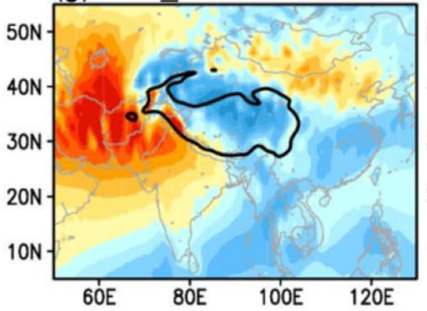

(k) HTAD_MJ/200 hPa

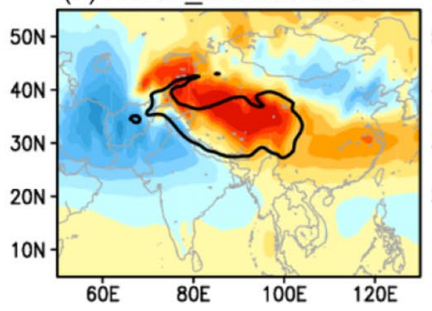

(d) $\mathrm{DH} \_\mathrm{MJ} / 550 \mathrm{hPa}$

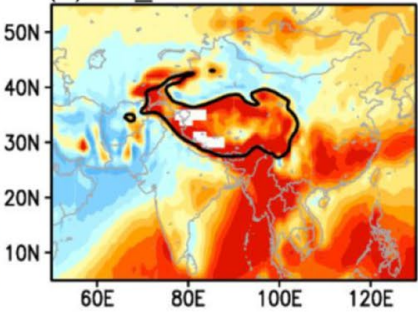

(h) $\mathrm{ADH} \quad \mathrm{MJ} / 550 \mathrm{hPa}$

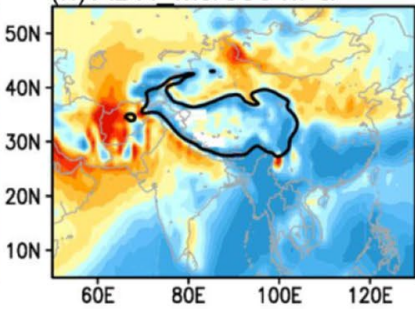

(I) HTAD_MJ/550 hPa

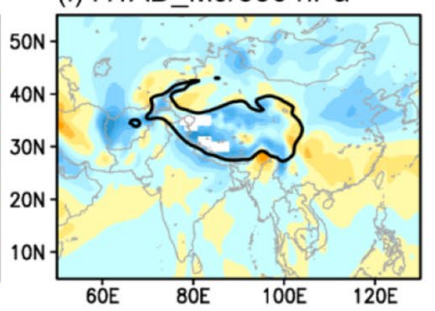

Fig. 9 Heat budget analyses at $200 \mathrm{hPa}$ and $550 \mathrm{hPa}$ in March-April (MA) (a-b, e-f, i-j) and May-June (MJ) (c-d, g-h, k-l) (Units: K day $\left.{ }^{-1}\right)$. a-d DH, (e-h) ADH, and (i-l) HTAD. The black solid curves denote the TP domain

Fig. 10 The vertical profiles of heat budget terms (DH: red line; ADH: black line; HTAD: blue line) within the TP domain (elevation higher than 3,000 m) during MA (a) and MJ (b). (Units: $\mathrm{K} \mathrm{day}^{-1}$ ) (a) MA

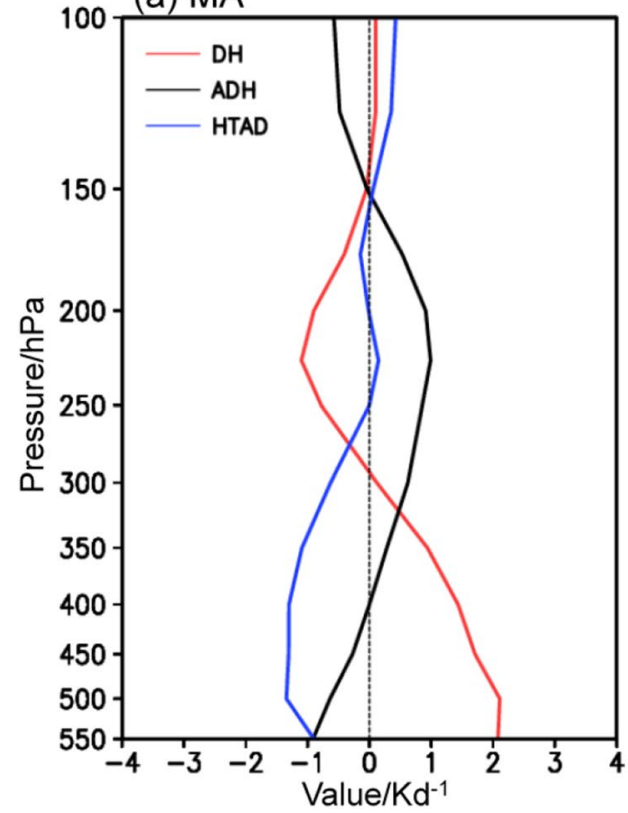

(b) $\mathrm{MJ}$

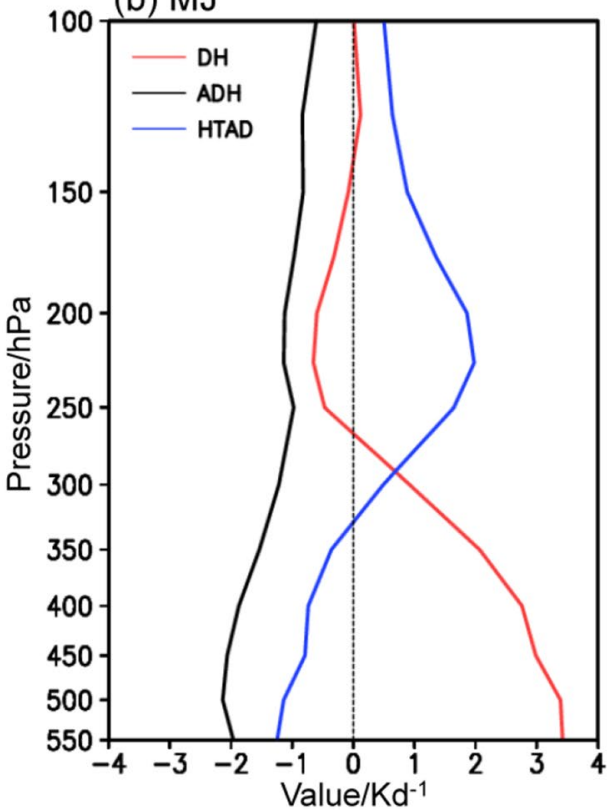


the lower-level formation resulting from local diabatic heating and the upper level formation resulting from adiabatic heating and horizontal warm advection. What are physical mechanisms for adiabatic heating and horizontal warm advection in the upper troposphere over the TP? The largescale atmospheric circulation and the heat budget terms in a meridional cross-section $\left(80-100^{\circ} \mathrm{E}\right)$ over the TP domain in MA and MJ are analyzed and results are shown in Fig. 11. Similar to the vertical distribution of WCOF in Fig. 6, dual $T^{\prime}$ centers (greater than $2 \mathrm{~K}$ ) are found in the upper troposphere around $200 \mathrm{hPa}$ over the southern slope of the TP and in the lower to middle troposphere (below $400 \mathrm{hPa}$ ) over the land surface (Fig. 11a). Surface diabatic heating extends upward to warm the lower-level atmosphere and leads to formation of the LLWCs, but it shows little effect around $200 \mathrm{hPa}$ over the TP even in MJ when the surface heating is more pronounced (Fig. 11b, f). This, once again, suggests that the formation of the ULWCs may come from other factors outside the plateau. The large-scale circulation shows significant descents in the troposphere over the southern TP in MA. These descents warm the upper troposphere through adiabatic heating process, and they are the downward branch of the local Hadley circulation, characterized by ascents around the equator with convergence in the lower troposphere and divergence in the upper troposphere (Fig. 11a). The tropical heating associated with strong ascents forms two meridional circulation cells: a southern cell with descents south of $20^{\circ} \mathrm{S}$, and a northern cell with descents in $30^{\circ} \mathrm{N}$. The latter one generates the ULWCs over the TP through adiabatic heating process in MA. A diabatic heating center is observed at $400 \mathrm{hPa}$ in equator (Fig. 11b), accompanied by strong upward flow. This middle-level diabatic heating is attributed to the intense latent heat release associated with tropical convection. Note that there is no significant warm center at the middle troposphere in equator (Fig. 11a), and this is mainly because the diabatic heating is largely compensated by the adiabatic cooling due to the strong upward motion (Fig. 11c). In MJ, as the accents dominate over the TP domain, the northern Hadley circulation cell disappears, but the southern branch maintains and extends northward (Fig. 11e). The accents over the TP lead to adiabatic cooling (Fig. 11g) and during this period, it is the horizontal advection that warms the air at $150-300 \mathrm{hPa}$ and generates the ULWCs (Fig. 11e, h). (a) T'_MA
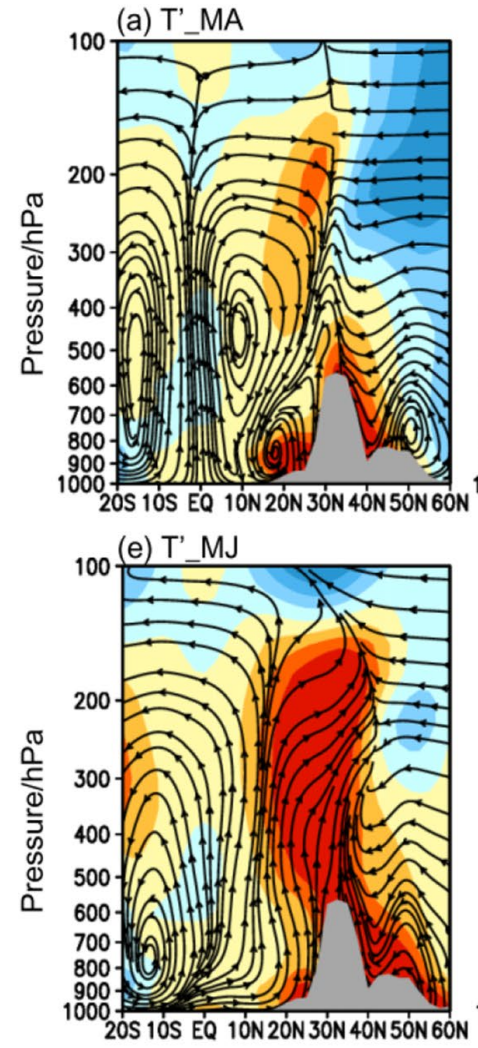

(b) DH_MA

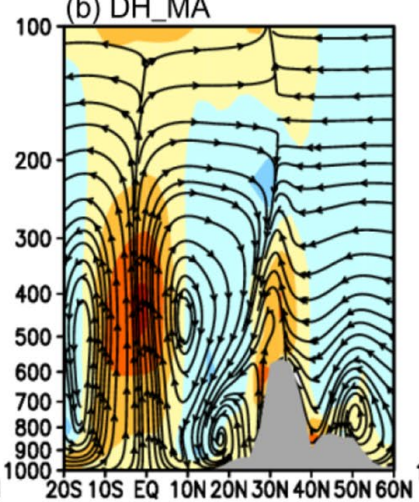

(f) DH_MJ

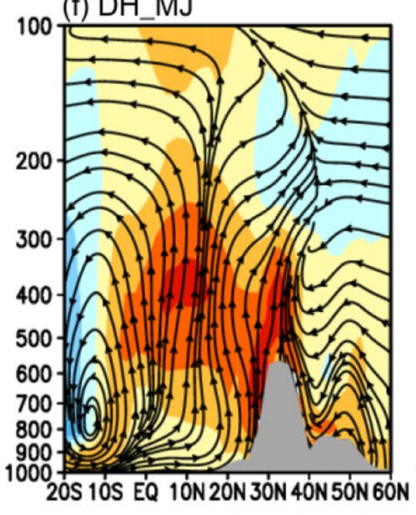

(c) $\mathrm{ADH}$-MA

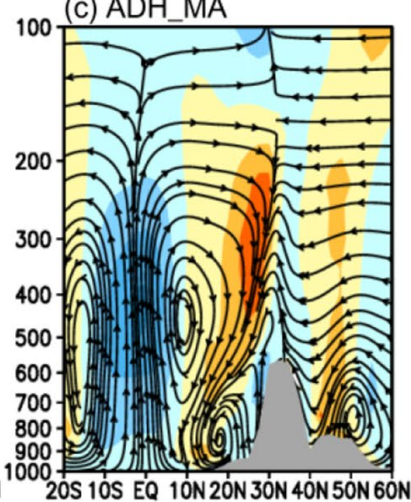

(g) $\mathrm{ADH} \_\mathrm{MJ}$

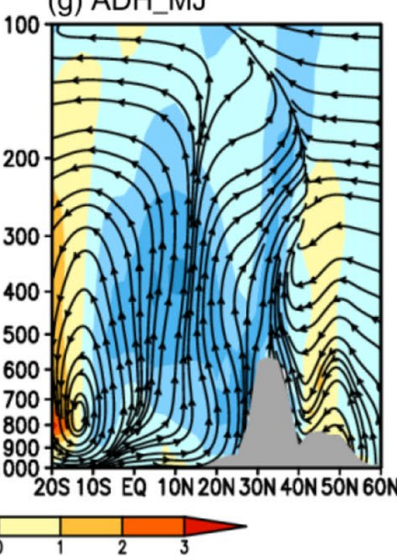

(d) HTAD_MA

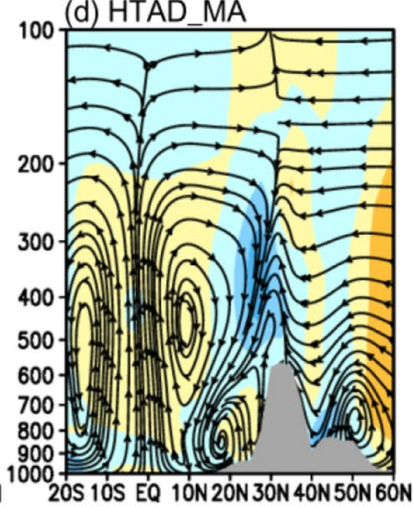

(h) HTAD_MJ

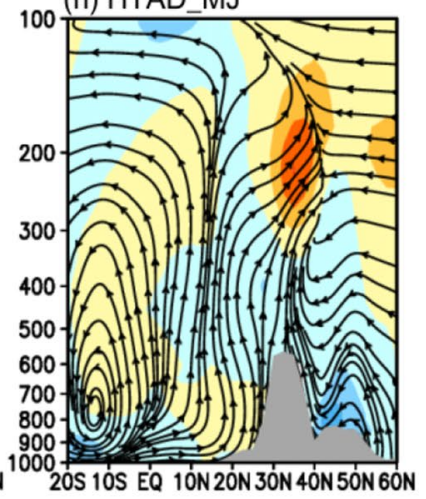

Fig. 11 Latitude-height (along $80-100^{\circ} \mathrm{E}$ ) cross sections of climatological $T^{\prime}$ (Units: $\mathrm{K}$; colored in $\mathbf{a}$, e), and meridional streamlines (meridional and vertical winds), and heat budget terms (Units: $\mathrm{K}$ day $^{-1}$; colored in $\left.\mathbf{b}-\mathbf{d}, \mathbf{f}-\mathbf{h}\right)$ in MA (a-d) and MJ (e-h). The color shading in (a) and (e), (b) and (f), (c) and (g), (d) and (h) denotes $T^{\prime}$, $\mathrm{DH}, \mathrm{ADH}, \mathrm{HTAD}$ respectively 


\subsection{Correlation analysis}

The contributions of heat budget terms to temperature changes in the upper and lower troposphere over the TP domain and the associated physical processes are analyzed in the above section. In this section, correlation analysis of interannual variations is performed to further evaluate identified physical processes and their relationships to the warm center formations at different levels.

The surface heat source (SHS) over the TP introduced by Ye and Gao (1979) is composed of the surface turbulent sensible heat flux, the surface latent heat from evaporation, and the surface effective radiation. In this regard, SHS is in fact the direct diabatic heating that comes from the ground and depicts the thermal effect of the TP itself rather than the multilevel diabatic heating term analyzed in the above sections. Hence we use SHS in this section to better describe the role of surface heating. Grid-to-grid correlation coefficients of interannual variations between $T^{\prime}$ and heat budget terms over the TP domain are shown in Fig. 12. The results indicate that correlations between lower-level (550-500 hPa) $T^{\prime}$ and SHS are robust and are statistically significant in large area over the TP. In MA, correlation coefficients are positive over the central and western TP, passing the 0.10 significance level (Fig. 12a). These positive correlations are much strengthened in MJ over the central and northwestern TP (Fig. 12c), when the SHS is enhanced during this period. However, the simultaneous correlations between $T^{\prime}$ and SHS are much weak in the upper layers, with no significant positive correlations between SHS and upperlevel $T^{\prime}$ (300-200 hPa) except near the peripheries of the TP (Fig. 12b, d). Figure 12f shows clearly that the upper-level air temperature variations are closely associated with adiabatic subsidence in MA, with significant simultaneous positive correlations prevailing in the central and southern TP. In MJ, the marked positive correlations between upper-level $T^{\prime}$ and horizontal advection are observed in the central and eastern TP, indicating the warm advection is the dominant process responsible for interannual variations in upper-level temperatures during 1979-2018 (Fig. 121). This is consistent with the climatological analyses in Sect. 4.1.

The above analyses on physical processes suggest that atmosphere over the TP is heated not solely by the land surface heating, but is driven concurrently by the "dual heating (a) $\mathrm{SHS} / 550-500 \mathrm{hPa} / \mathrm{MA}$

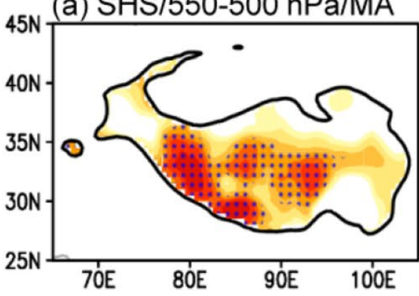

${ }_{45 \mathrm{~N}}$ (e) $\mathrm{ADH} / 550-500 \mathrm{hPa} / \mathrm{MA}$

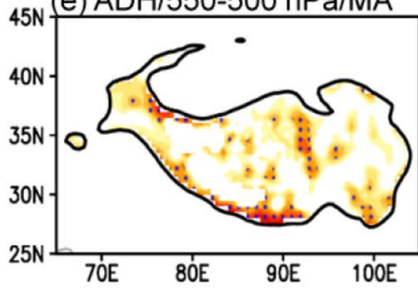

45N (i) HTAD/550-500 hPa/MA

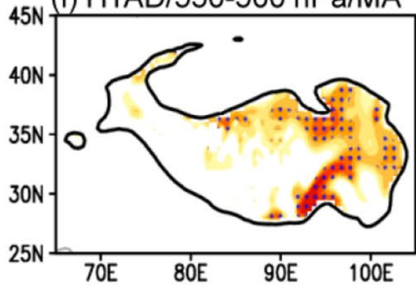

(b) $\mathrm{SHS} / 300-200 \mathrm{hPa} / \mathrm{MA}$

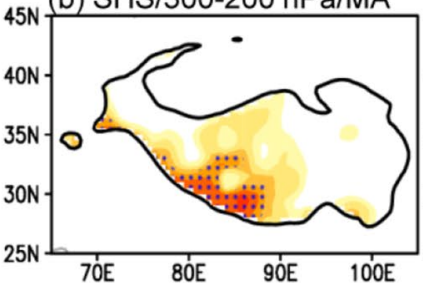

(f) $\mathrm{ADH} / 300-200 \mathrm{hPa} / \mathrm{MA}$
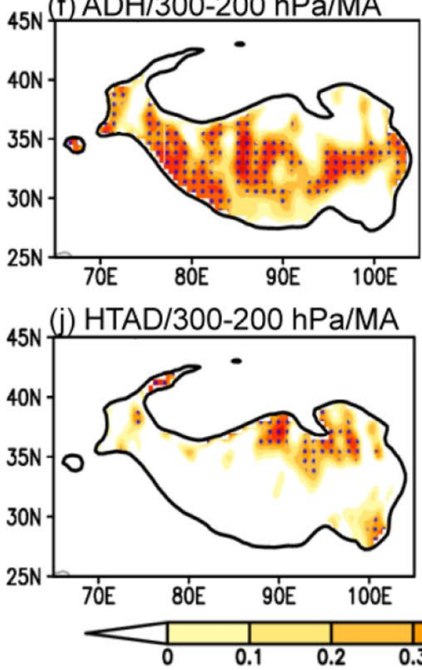

(c) SHS/550-500hPa/MJ

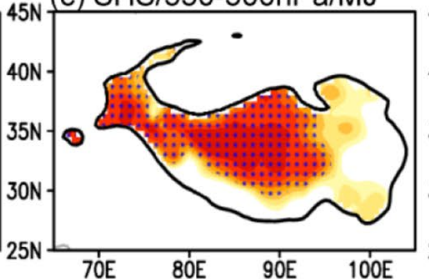

(g) $\mathrm{ADH} / 550-500 \mathrm{hPa} / \mathrm{MJ}$

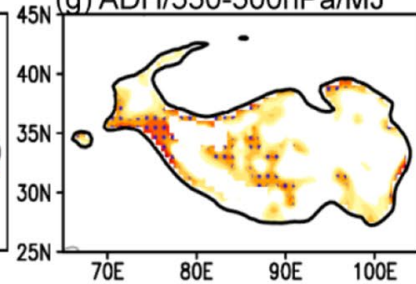

(k) HTAD/550-500hPa/MJ

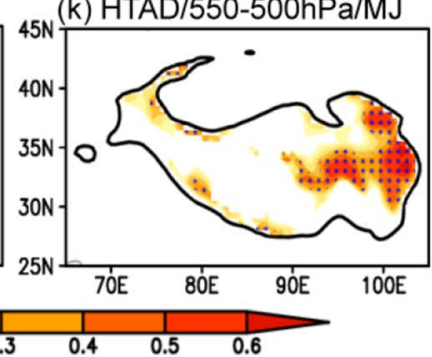

(d) $\mathrm{SHS} / 300-200 \mathrm{hPa} / \mathrm{MJ}$

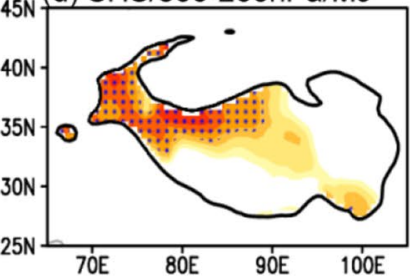

(h) $\mathrm{ADH} / 300-200 \mathrm{hPa} / \mathrm{MJ}$
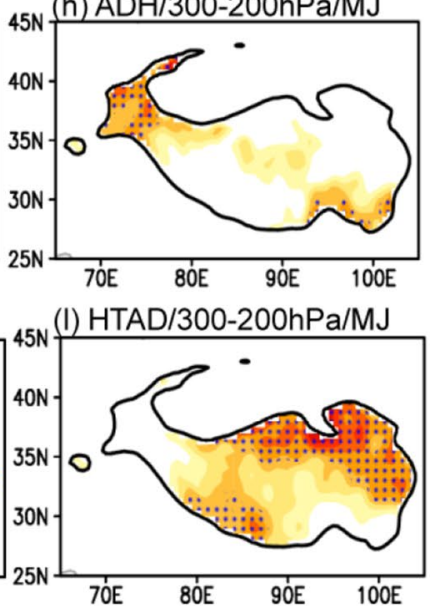

Fig. 12 Distribution of grid-to-grid correlation coefficients between interannual variations of $T^{\prime}$ and heat budget terms averaged for MA (a-b, e-f, i-j) and MJ (c-d, g-h, k-l) during 1979-2018. a-d denotes the correlation coefficients between the SHS and $T^{\prime}$ (a, c for 550-500 hPa $T^{\prime} ; \mathbf{b}, \mathbf{d}$ for 300-200 hPa $T^{\prime}$ ). e-h denotes the correlation coefficients between $\mathrm{ADH}$ and $T^{\prime}$ at corresponding tropospheric levels (e, g for $550-500 \mathrm{hPa} ; \mathbf{f}, \mathbf{h}$ for $300-200 \mathrm{hPa}$ ); (i)-(l) is the same with (e)-(h), but for HTAD and $T^{\prime}(\mathbf{i}, \mathbf{k}$ for $550-500 \mathrm{hPa} ; \mathbf{j}$, I for 300 $200 \mathrm{hPa}$ ). Only the positive correlations are shown, and the stippled areas denote correlation coefficients above the $90 \%$ confidence level. The black solid curves represent the TP domain 
effect" (Tamura et al. 2010) around the TP. The LLWCs are generated due to the surface diabatic heating while the ULWCs are generated and maintained by adiabatic heating and warm advection associated with large-scale circulation.

\subsection{The effect of the TP surface thermal condition}

The daily time series of SHS and $550 \mathrm{hPa}$ (or $200 \mathrm{hPa}$ ) temperature within the TP domain (elevation greater than $3000 \mathrm{~m}$ ) during period from February to May in a given year are used to calculate their lead-lag correlations, and time variations of these correlations during 1979-2018 are shown in Fig. 13.

The correlation coefficients between SHS and $550 \mathrm{hPa}$ temperature peak when the SHS leads the temperature by 1-4 days with a maximum correlation coefficient of 0.9 (Fig. 13a). The correlation coefficients are considerably reduced when the SHS lags the temperature. In contrast, the lead-lag correlations are relatively small between SHS and $200 \mathrm{hPa}$ temperature (Fig. 13b), and no systematic significant lead or lag correlations are found between them. Thus, the SHS perturbation directly leads to the variation of lower-level temperature, but it has little warming effect on the upper-level temperature.

Furthermore, two years (1989 and 2005) are selected arbitrarily to explore the heating effect of the surface thermal conditions over the TP domain on the tropospheric temperature changes, based on the ERA-5 hourly temperature data. The hourly lead-lag correlation coefficients between temperature at $550 \mathrm{hPa}$ and temperatures at levels above are computed (Fig. 14). The lead-lag correlations in the two years give very similar features and they indicate that the surface temperature perturbation can propagate upward from the surface within $3 \mathrm{~h}$ but is generally confined below $300 \mathrm{hPa}$. The time lag of peak correlation coefficients increases with height, with the coefficients attaining their maxima at the lag time of $+1,+2$ and $+3 \mathrm{~h}$ at $550 \mathrm{hPa}, 450-400 \mathrm{hPa}$, and 350-300 hPa, respectively. Notably, the magnitude of peak correlation coefficient decreases gradually with height and no peak is observed above $300 \mathrm{hPa}$. This further implies that the lower-level temperature is sensitive to the surface disturbances, while upper-level temperature is barely influenced by the underlying surface thermal state.

The time series of regional mean warm core intensity index at $550 \mathrm{hPa}$ is obtained by averaging the intensity of the total warm cores within the TP domain in March-June and is linearly detrended to remove the warming trend during 1979-2018. Surface variables over the TP are regressed onto the detrended warm core index to determine how the lower-level warm cores are related to the local surface thermal conditions at the interannual time scale (Fig. 15). These regression analyses show that strong LLWCs are associated with enhanced shortwave radiation reaching the surface of the TP. The enhanced shortwave radiation leads to surface warming. According to Stefan-Boltzmann's law, the heated ground tends to emit more energy into the atmosphere, thus the longwave radiation emitted by the surface increases. In addition, the heated ground also enhances the temperature differences between the ground surface and the surface air, which leads to the increase of surface sensible heat flux. The enhancement of surface upward longwave radiation and sensible heat flux further strengthen the SHS over the TP. Consequently, more energy from the ground surface is transmitted upward to the atmosphere, and this leads to the increase in the lower-level air temperature and the enhancement of the warm core intensity. It should be noted that the

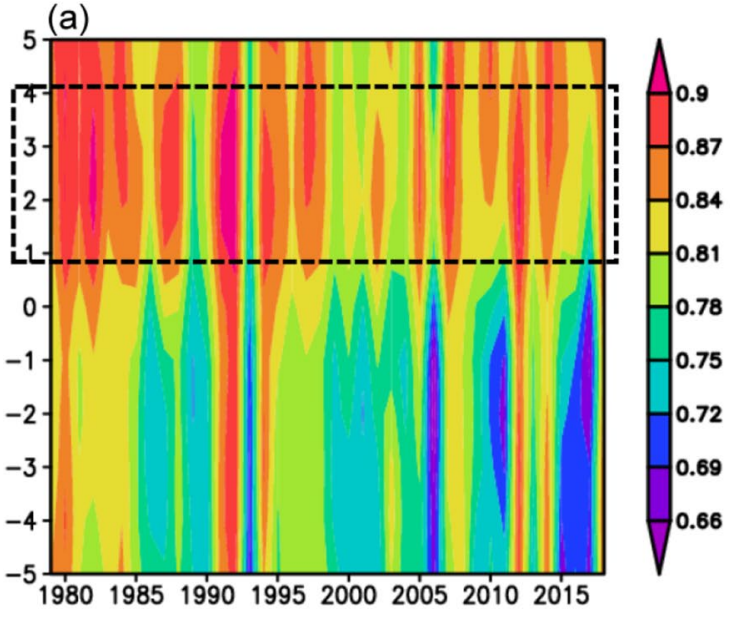

Fig. 13 a Lead-lag correlation coefficients between daily SHS and $550 \mathrm{hPa}$ temperature during period from February to May within the TP domain in each year of 1979-2018. b Same as (a), but for $200 \mathrm{hPa}$

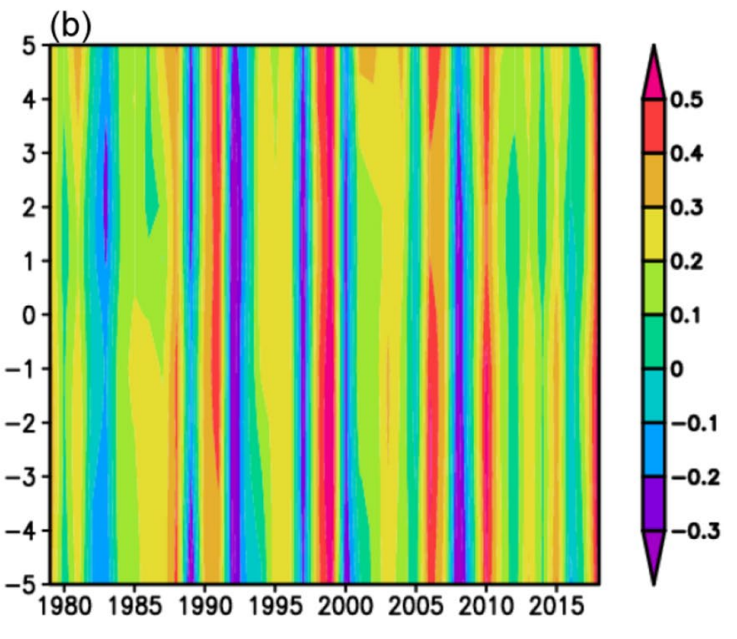

temperature. Positive (negative) values in y-axis denote number of days when temperature is lagging (leading) SHS 


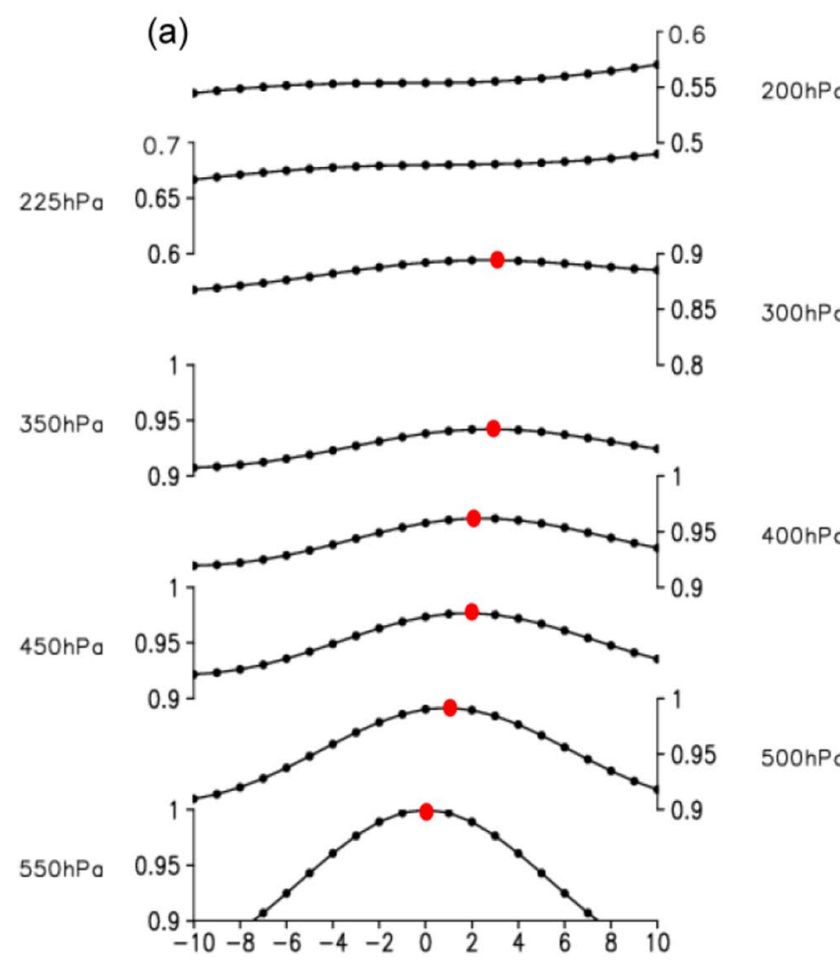

Fig. 14 Lead-lag correlation coefficients within $10 \mathrm{~h}$ between hourly $550 \mathrm{hPa}$ temperature and temperature at upper levels during period from March to June within the TP domain in 1989 (a) and 2005 (b).

significant positive heat fluxes and temperature anomalies are mostly concentrated in $80-95^{\circ} \mathrm{E}$, where the LLWCs occur most frequently. Although there are also areas (east of $95^{\circ} \mathrm{E}$ ) where the warm anomalies occur with weak heat fluxes (due to the condensation heat release around $400 \mathrm{hPa}$ ), their correlations are much weaker. Therefore, the formation and variation of the LLWCs are directly and significantly modulated by the TP surface thermal condition.

\subsection{The association of the ULWCs with the large-scale atmospheric circulation}

As illustrated in the above sections, different from the LLWCs, the ULWCs are controlled by adiabatic subsidence (in MA) and warm horizontal advection (in MJ). In this section, we further investigate how the adiabatic heating and horizontal advection are associated with the large-scale circulation. In MA, the climatological-mean upper-level divergence center is over the Indo-Pacific warm pool and it corresponds to the strong upward motion. This upper level divergence center is associated with the westward flows that lead to convergence in the region south of the TP, inducing significant subsidence (Fig. 16a). The convergence and subsidence band in $25^{\circ} \mathrm{N}$ corresponds well with the preferred upper-level warm core occurrence region in the southern $\mathrm{TP}$, implying the dominating role of adiabatic descending

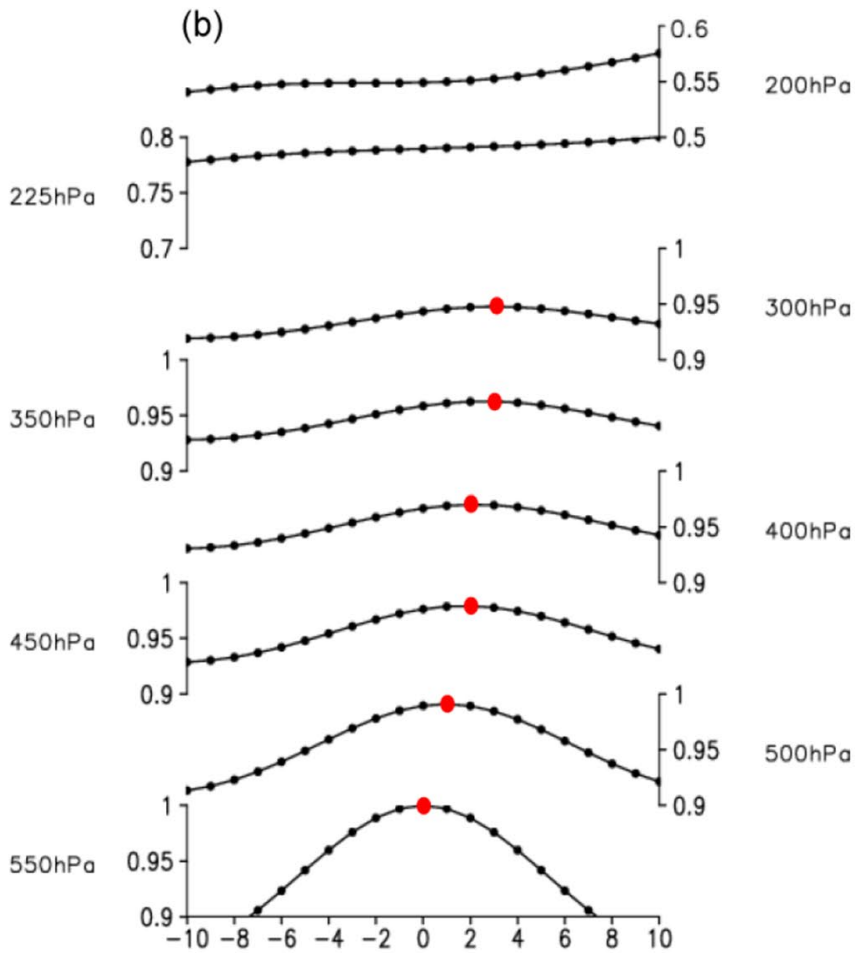

Positive (negative) values in $\mathrm{x}$-axis denote number of hours when the upper-level temperature is lagging (leading) $550 \mathrm{hPa}$ temperature, and the red dots denote correlation maximum at each level

motion in generating warm cores. In MJ, with the poleward advance of insolation increase, the strong divergence center over the warm pool shifts northward to $10^{\circ} \mathrm{N}$; the convergence zone with intense subsidence (previously positioned over the southern TP and to its southwest in MA) migrates northwestward to the Iranian Plateau. During this period, the South Asian High has not yet migrated northward to the Iranian-Tibetan Plateau, but maintains in the extratropical area to the south of the TP (approximately $20^{\circ} \mathrm{N}$ ) (figures not shown). The westerly prevails in the northern flank of South Asian High, and the downstream TP is intensely heated through the warm westerly advection.

The $200 \mathrm{hPa}$ regional mean warm core intensity index is computed in the same way as $550 \mathrm{hPa}$, but is separately calculated in MA and MJ during 1979-2018. These time series are also linearly detrended and regression patterns of some variables against them are shown in Fig. 17. The results show some good correspondences with the climatological mean fields (Fig. 16). The stronger than normal upper-level warm cores over the TP (both in MA and MJ) are associated with anomalous descents and convergence 

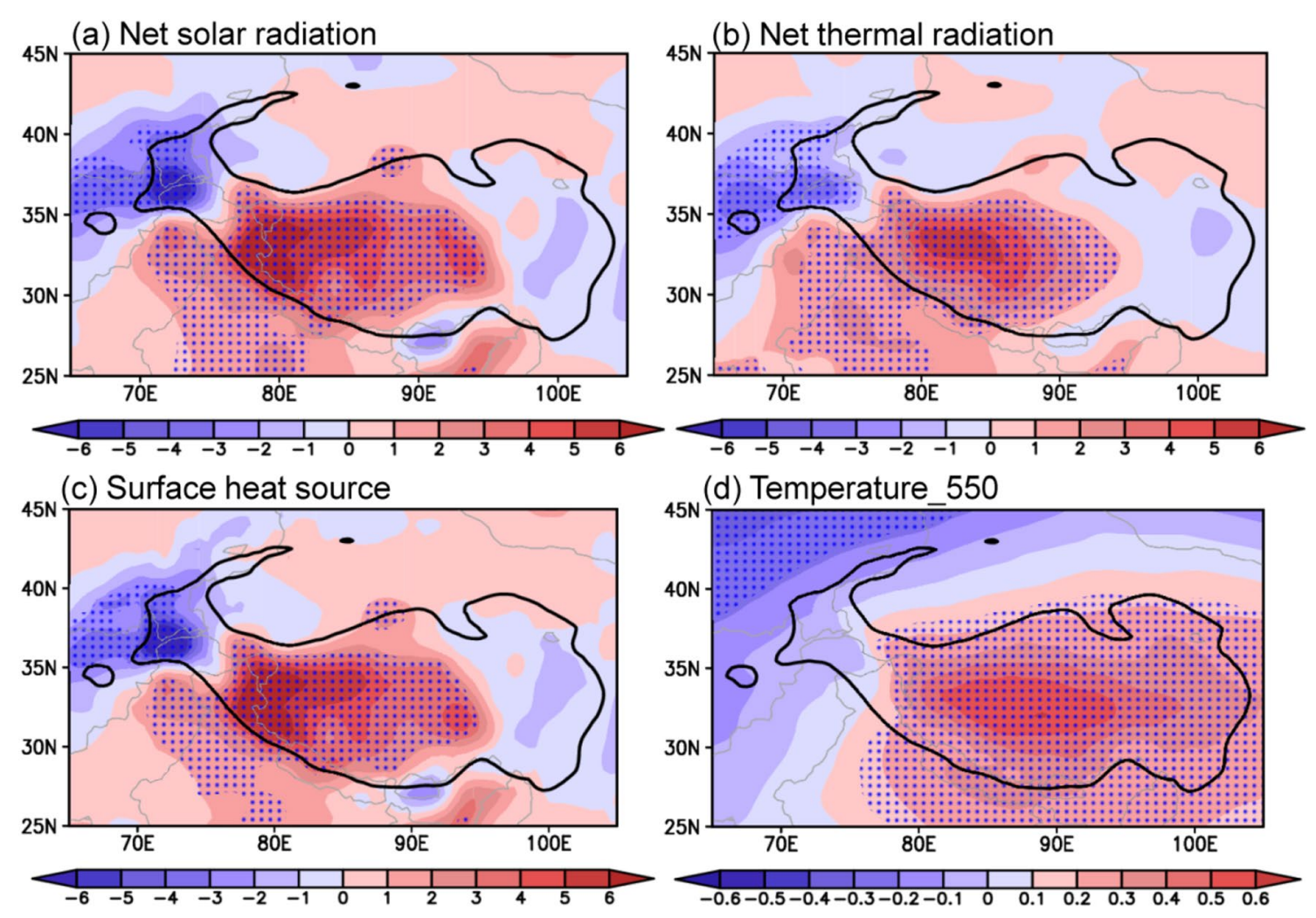

(d) Temperature_550

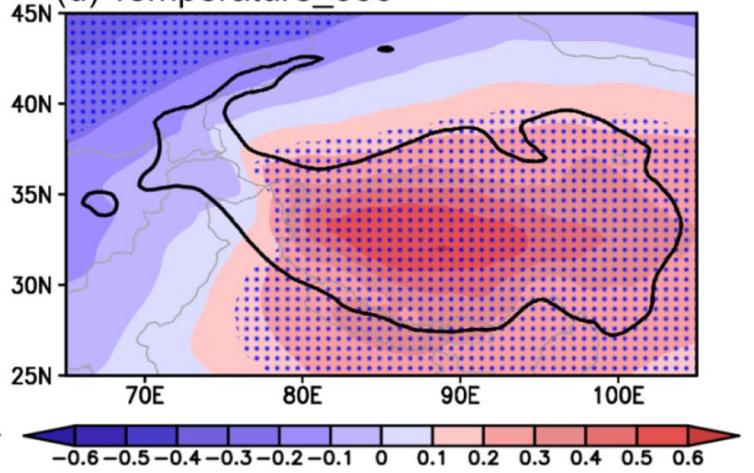

Fig. 15 Simultaneous regression fields of (a) surface net solar radiation (Units: $\mathrm{W} \mathrm{m}^{-2}$ ), (b) surface net thermal radiation (Units: $\mathrm{W} \mathrm{m} \mathrm{m}^{-2}$ ), (c) surface heat source (SHS) (Units: $\mathrm{W} \mathrm{m}^{-2}$ ) and (d) $550 \mathrm{hPa}$ temperature (Units: K) averaged for March-June against the

detrended $550 \mathrm{hPa}$ warm core intensity index during 1979-2018. The stippled areas denote passing the $90 \%$ confidence level. Downward is positive in (a) and upward is positive in (b) and (c). The black solid curves represent the TP domain
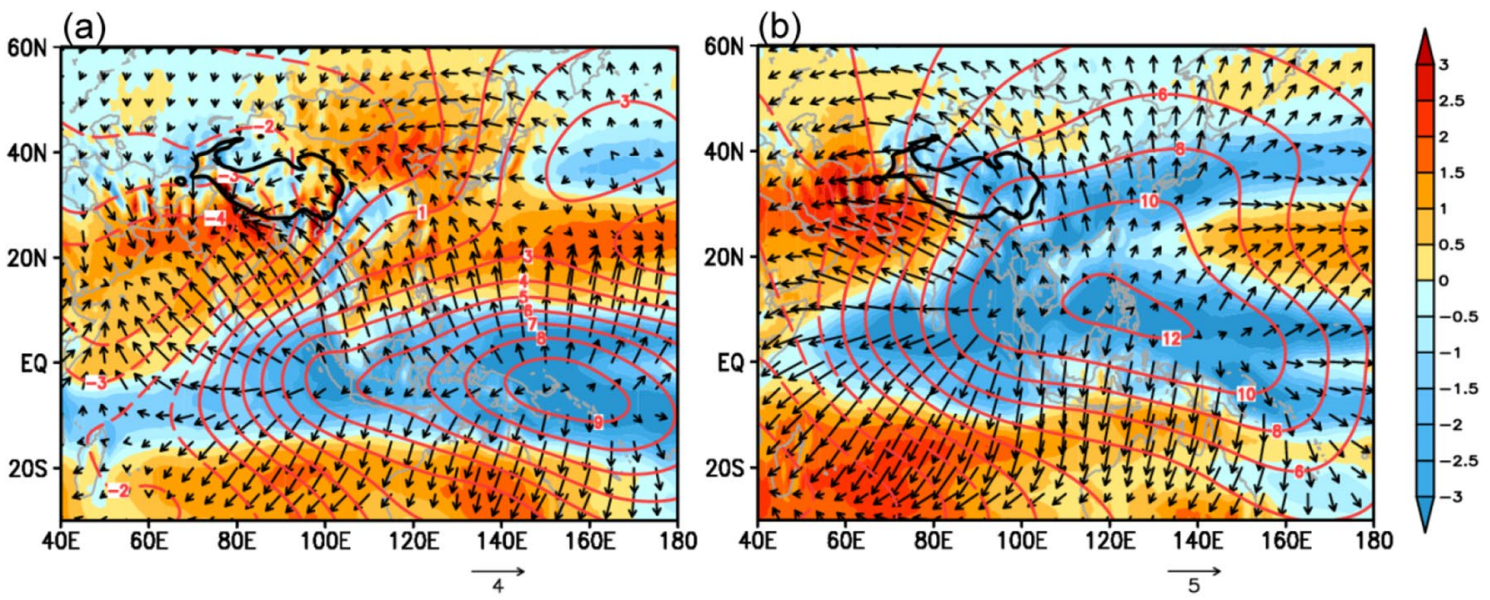

Fig. 16 The climatological-mean $200 \mathrm{hPa}$ divergent wind (vectors, units: $\mathrm{m} \mathrm{s}^{-1}$ ), velocity potential (contour, units: $10^{6} \mathrm{~m}^{2} \mathrm{~s}^{-1}$ ) and vertical velocity (colored, $0.01 \mathrm{~Pa} \mathrm{~s}^{-1}$ ) fields in MA (a) and MJ (b). The black solid curves represent the TP domain

in the upper troposphere (Fig. 17). These circulation anomalies are closely associated with anomalous upper level divergent flows over the Indo-Pacific warm pool. They are triggered by the local deep convection with low OLR center over the eastern Bay of Bengal and the Sulu
Sea. In MA, the convection-induced divergent flows converge over the TP in the upper troposphere, accompanied with notable anomalous descends with a band of positive OLR anomalies over the southern TP and to its southwest (Fig. 17a, b). Such dynamically forced upper-level 


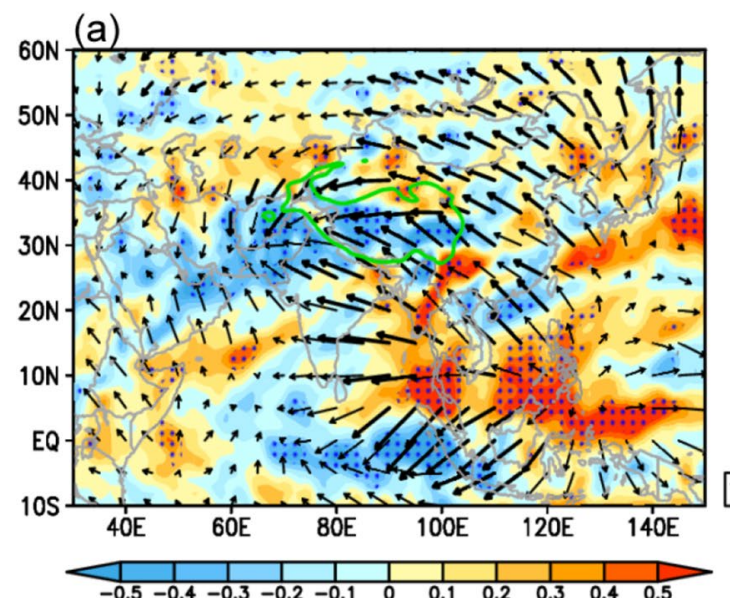
(c)

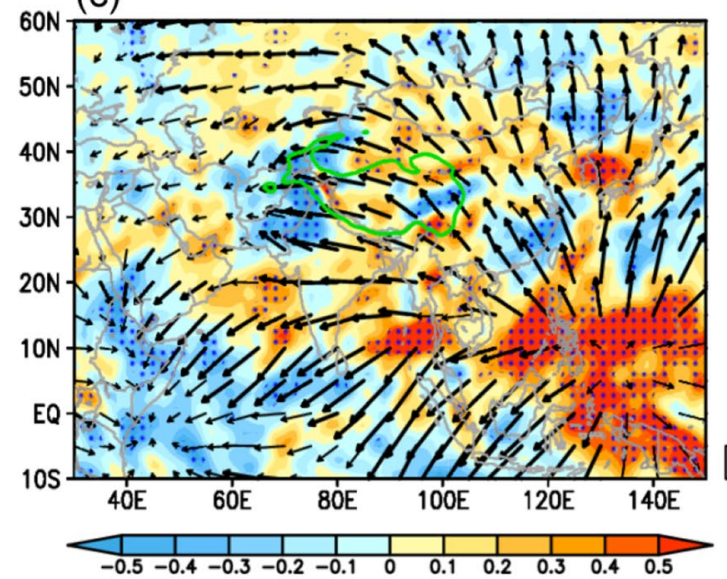

Fig. 17 Simultaneous regression fields of some climate variables against the detrended $200 \mathrm{hPa}$ warm core intensity index in MA (a, b) and MJ (c, d) during 1979-2018. a $200 \mathrm{hPa}$ divergent wind (vector, units: $\mathrm{m} \mathrm{s}^{-1}$ ) and divergence (colored, units: $10^{-6} \mathrm{~m}^{-1}$ ) in MA. b $200 \mathrm{hPa}$ vertical velocity (colored, units: $0.01 \mathrm{~Pa} \mathrm{~s}^{-1}$ ) and OLR (contour, units: $\mathrm{W} \mathrm{m}^{-2}$ ) in MA. c same as a, but for MJ. d $200 \mathrm{hPa}$ zonal

convergence and subsidence are also responsible for interannual variations of the ULWC intensity. In MJ, anomalous divergent winds, which are maintained by the warm pool convection, converge in the western flank of the TP. During this period, anomalous westerly horizontal warm advection leads to further development of the ULWC intensity (Fig. 17c, d).

Based on the above analyses, we conclude that the ULWCs and their variations are dominated by the convection-triggered circulation, that is to say, the ULWCs can be well generated without the heating effect of the TP, which is different from the LLWCs. The formation of the ULWCs and their variations are a result of thermal response to the tropical convective condensation heating. As Randel and Park (2006) proposed, the structure of upper tropospheric temperature around the $\mathrm{TP}$ in response to the tropical convection is consistent with
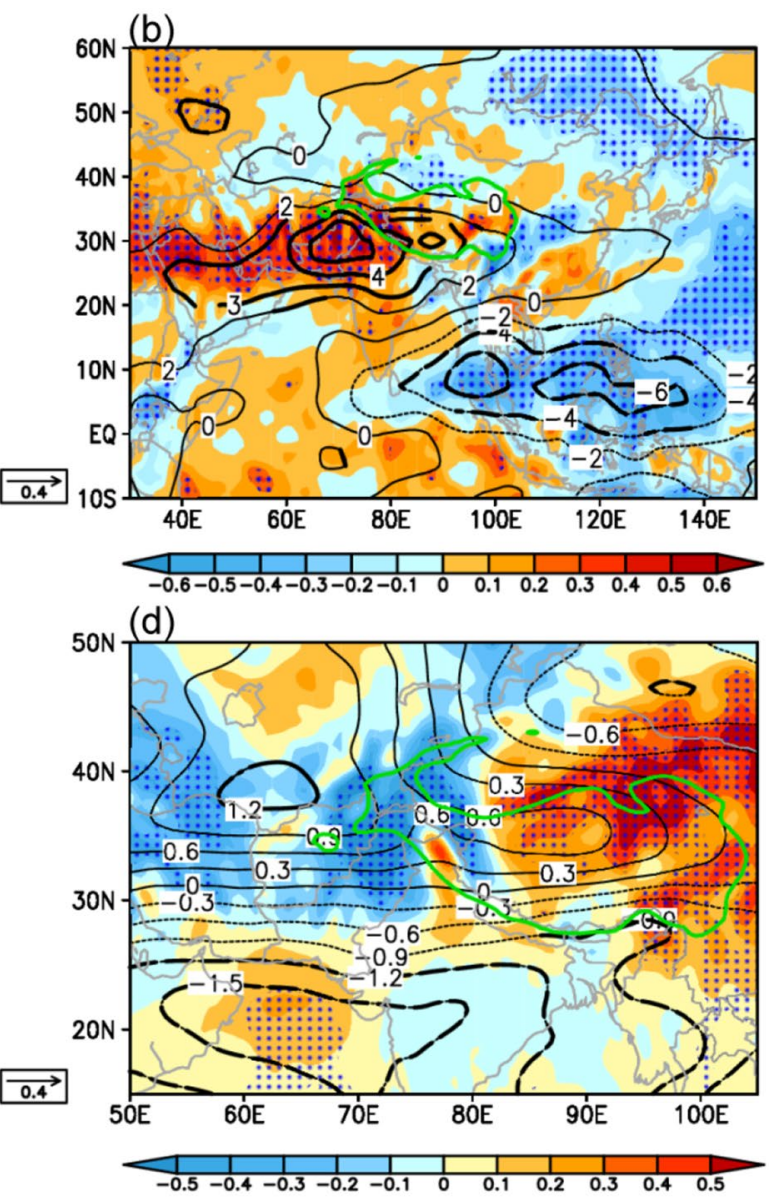

wind (contour, units: $\mathrm{m} \mathrm{s}^{-1}$ ) and horizontal temperature advection (colored, units: $\mathrm{K} \mathrm{day}^{-1}$ ) in MJ. The bold vector, bold contour and stippled areas denote regions where regression passing the significance test at the $90 \%$ confidence level. The green solid curves represent the TP domain

the large-scale Gill type response to an off-equatorial heating (Gill, 1980; Hoskins and Rodwell 1995).

\section{Summary and discussion}

The present study has examined the tropospheric warm cores around the TP based on the analysis of 40-year (1979-2018) ERA-interim 6-hourly reanalysis data. Two different types of warm cores are obtained: the lowerlevel warm cores (LLWCs) and the upper-level warm cores (ULWCs). The climatological features and physical mechanisms of these two types of warm cores have been elucidated and compared. The conclusions can be summarized as follows. 
(1) The LLWCs are confined below $450 \mathrm{hPa}$, while the ULWCs are concentrated at $200-400 \mathrm{hPa} .450-400 \mathrm{hPa}$ is the border layer separating the two types of warm cores. The active region of the LLWCs is concentrated within the interior of the TP $\left(80-100^{\circ} \mathrm{E}, 28-38^{\circ} \mathrm{N}\right)$ and is characterized by regional patches with high frequency occurrences. Whereas the ULWCs are frequently observed within a zonally elongated band in the central-southern $\mathrm{TP}$ and its vicinity $\left(60-110^{\circ} \mathrm{E}\right.$, $\left.25-35^{\circ} \mathrm{N}\right)$.

(2) March-October is the active phase for tropospheric warm core occurrences, but timing of the active phase is altitude dependent. Warm cores at $550 \mathrm{hPa}$ are the earliest to enter the active phase (in middle February), followed by the warm cores at $200 \mathrm{hPa}$ (in early March), and the warm cores at $400 \mathrm{hPa}$ are the latest to enter the active phase (in middle May). The LLWCs and ULWCs are vertically separated and independent of each other in winter, spring and autumn, but they merge into a single one in July and August. Both the LLWCs and ULWCs grow fastest from March to June, a critical period for the warm core development.

(3) The LLWCs mostly occur within the TP and have a modest seasonal variability during their active phase. The locations of their high occurrence shift slightly $\left(<3^{\circ}\right)$ in meridional direction and migrate by $6^{\circ}$ to the western TP in summer. In contrast to the LLWCs, the location variations of the ULWC high occurrences are much more pronounced. In boreal summer, the ULWCs exhibit a marked northward shift (approximately $7^{\circ}$ ) and a westward displacement (approximately $12^{\circ}$ ).

(4) The physical mechanisms for the LLWCs and ULWCs are different. Formation and variation of the LLWCs are mainly driven by the TP surface heating. From March to June, the intense diabatic heating from the underlying ground leads to development, maintenance and amplification of the warm condition at lower levels. Significant positive correlations are found between the surface heat source (SHS) and the $550 \mathrm{hPa}$ temperature when the SHS leads the $550 \mathrm{hPa}$ temperature by 1-4 days. The local SHS heating directly leads to the near-surface air temperature disturbances, and results in upward extension of warming in the lower troposphere. The relationships between the interannual variations of LLWCs intensities and surface radiation fluxes further indicate that anomalously strong LLWCs are associated with enhanced surface net solar radiation, net thermal radiation, and SHS. However, no systematic correlations are found between SHS and upper-level air temperature. Instead of directly heated by the underlying surface, the ULWCs are associated with the large-scale atmospheric circulation and are primarily controlled by adiabatic descending heating over the central and southern TP in March-April. This intense descending motion around the TP is induced by the regional upper-level convergence, a result of the divergent wind over the Indo-Pacific warm pool triggered by the local convection. In May-June, the westerly wind advects warm air to the downstream TP, which amplifies and maintains warm cores.

The tropospheric warm cores over the TP are unique climate phenomena and the TP thermal condition has long been recognized as a forcing factor of Asian summer monsoon establishment and precipitation variation over East Asia. In previous studies, the vertically averaged temperature of $500-200 \mathrm{hPa}$ is taken to represent the TP thermal condition. This index is extensively applied in many studies to investigate the role of the TP in determining the summer monsoon onset (He et al. 1987; Li and Yanai 1996; Chou 2003) and the seasonal northward jump of westerly jet ( $\mathrm{Li}$ et al. 2004; Li and Pan 2006). However, in view of the different physical mechanisms of warm cores in the lower and upper troposphere presented in this study, the past knowledge with respect to the thermal structure of the TP is somehow limited. Warm cores around the TP cannot be attributed solely to the underlying surface heating; the concurrent "dual heating" mechanism (Tamura et al. 2010) is responsible for the formation and development of the independent warm cores in the lower and upper troposphere. Generated by the surface diabatic heating, the LLWCs directly reflect the thermal condition of the TP. On the other hand, the ULWCs are dominated by the large-scale circulation triggered by tropical convection in the Indo-Pacific warm pool, so the upperlevel warming is in fact an indirect reflection of the air-sea interaction in remote regions outside the TP domain. In this sense, it is debatable to take the simple vertical average of 500-200 hPa temperature as the heating index of the TP.

The physical mechanisms for the formation of the warm cores discussed in this study are mainly focused on the period of March-June during which the ULWCs within the TP domain occur most frequently and attain their maximum intensities. It is worth mentioning that the physical mechanisms of the warm cores in peak summer (July-August) are consistent with those in March-June. Climatological and regression analyses indicate that the LLWCs and ULWCs are still distinct from each other even in peak-summer season (refer to Figs. S2-S7 in the supplementary information). In the traditional theory, the vertically averaged $(500-200 \mathrm{hPa})$ temperature (or $T^{\prime}$ ) is taken to represent the thermal condition of the TP (e.g., Li and Yanai, 1996), and the vertically averaged large warm center is situated right over the TP domain (Figs. S2 a, d). However, the spatial distributions of the warm cores in peak-summer are very different at the upper and lower levels: the $550 \mathrm{hPa}$ warm cores are maintained within the TP domain (Fig. S2 b, e); in contrast, the 
$200 \mathrm{hPa}$ warm cores are no longer situated within the main body of the TP but shift considerably westward to the Pamirs Plateau and its west (Fig. S2 c, f). These differences between the upper and lower levels are clearly shown both in the $T^{\prime}$ /temperature field (Fig. S2) and the WCOF field (Fig. S3). Heat budget analyses indicate that, during July-August, the lower-level diabatic heating overwhelms the adiabatic cooling and cold advection over the TP domain (Figs. S4 d-f and S5 a). Regression analyses (Fig. S6) further suggest that, strong LLWCs in mid-summer are also strongly associated with enhanced shortwave radiation, net thermal radiation and SHS. Consistent with analyses in March-June, the formation and variation of the LLWCs in mid-summer are also directly and significantly modulated by the surface thermal condition. Note that in mid-summer, the $200 \mathrm{hPa}$ ULWCs are no longer situated over the TP but shift westward to the Central Asia $\left(61-79^{\circ} \mathrm{E}\right.$ and $36-46^{\circ} \mathrm{N}$, the black box in Fig. S3b). Similar analyses are carried out over the Central Asia in July-August. Results indicate that the developments of the ULWCs in mid-summer can also be attributed to the largescale circulation: the upper-level air is significantly warmed through adiabatic heating and warm advection (Fig. S4 b-c and Fig. S5b), with a strong subsidence center dominating the western part of the Central Asia and the warm advection dominating the eastern part. Climatological divergent wind (Fig. S7a) and divergent wind regressed to the ULWC intensity index (Fig. S7b) suggest that strong ULWCs during this period are associated with the enhanced upper-level descents and convergence (Figs. S7 b-c) over the Central Asia, which also originate from the upper-level divergence over the Indo-Pacific warm pool (Fig. S7 a-b). During this period, an anomalous horizontal warm advection (Fig. S7d) leads to the downstream enhancement of the intensity of the ULWCs. It is noteworthy, however, that the summer monsoon reaches its peak phase in July-August, during which the precipitation associated with the Asian summer monsoon thrives in the eastern TP; upper-level divergence triggered by precipitation over the eastern TP (Fig. S7b) may also play a role in generating the strong subsidence in the Central Asia.

We tend to pay particular attention to the March-June season mainly because this is the critical period for the active occurrences of both the LLWCs and the ULWCs (within the TP domain). During this period, the two types of warm cores are vertically decoupled in March-June, with a clear separation observed at $400-450 \mathrm{hPa}$. As Duan et al. (2005) once proposed, the TP can be considered "an isolated heat source throughout April to June". This indicates that in spring to early summer, the thermal effect of the TP might be more independent compared with that in peak summer season. During July to August, with the full onset of the Asian summer monsoon, the subtropical large-scale circulation patterns change drastically, and the thermal condition of the TP is considerably influenced as well. Thus, during July to August, it might be hard to separate the roles of the TP thermal effect and large-scale atmospheric circulation.

In this study, we identified two independent types of warm cores, and investigated the mechanisms for their formation, amplification and maintenance. Their respective and synergistic effects on climate are not discussed and need to be further examined in future. Moreover, the close connection of interannual variations between the ULWCs and the convection over the Indo-Pacific warm pool implies that the ULWCs are possibly modulated by El Nino Southern Oscillation (ENSO) events (Dai et al. 2013). In contrast, the low-level temperature over the TP, which is largely modulated by surface diabatic heating, is probably less influenced by ENSO at the interannual time scale. Based on the recent studies, the North Atlantic Oscillation ( $\mathrm{Li}$ et al. 2008), North Atlantic sea surface temperature anomalies (Cui et al. 2015), and Indian Ocean forcing (Zhao et al. 2018) are also considered to be responsible for the interannual variability of the thermal condition over the TP. Detailed investigations are needed to further assess the different effects of ENSO on variations of lower and upper level warm cores.

Supplementary Information The online version contains supplementary material available at https://doi.org/10.1007/s00382-021-05749-1.

Acknowledgements The first author is thankful to Dr. Zhiwei Zhu and Dr. Zhengguo Shi for their valuable suggestions. We thank the European Centre for Medium-Range Weather Forecasts (ECMWF) for the use of the ERA-interim and ERA-5 data, the National Ocean and Atmosphere Administration (NOAA) for the use of the outgoing longwave radiation (OLR) data, the Chinese Meteorological Administration (CMA) for the use of in situ observations and radiosonde data. Thanks are also extended to two anonymous reviewers for their constructive comments and suggestions. This research was jointly supported by the Strategic Priority Research Program of Chinese Academy of Sciences (XDB40030100, XDA20070103) and the National Natural Science Foundation of China (41991254, 41690115). BD is supported by the U.K. National Centre for Atmospheric Science-Climate (NCASClimate) at the University of Reading.

Data availability The ERA-interim and ERA-5 data can be downloaded from https://apps.ecmwf.int/datasets/data/interim-full-daily/ and https://cds.climate.copernicus.eu/cdsapp\#!/dataset/reanalysisera5-pressure-levels?tab=overview/. The OLR data can be obtained from the website of http://www.esrl.noaa.gov/psd/data/gridded/data. ncep.reanalysis.html. In situ observations and radiosonde data can be obtained from the website of http://data.cma.cn/.

Code availability Codes used for the analyses in this study are available from corresponding authors upon request. 


\section{Declarations}

Conflicts of interest The authors declare that there is no conflict of interest regarding the publication of this paper.

Open Access This article is licensed under a Creative Commons Attribution 4.0 International License, which permits use, sharing, adaptation, distribution and reproduction in any medium or format, as long as you give appropriate credit to the original author(s) and the source, provide a link to the Creative Commons licence, and indicate if changes were made. The images or other third party material in this article are included in the article's Creative Commons licence, unless indicated otherwise in a credit line to the material. If material is not included in the article's Creative Commons licence and your intended use is not permitted by statutory regulation or exceeds the permitted use, you will need to obtain permission directly from the copyright holder. To view a copy of this licence, visit http://creativecommons.org/licenses/by/4.0/.

\section{References}

Bao XH, Zhang FQ (2013) Evaluation of NCEP CFSR, NCEP-NCAR, ERA-Interim, and ERA-40 reanalysis datasets against independent sounding observations over the Tibetan Plateau. J Clim 26:206214. https://doi.org/10.1175/JCLI-D-12-00056.1

Bollasina M, Nigam S (2011) The summertime "heat" low over Pakistan/northwestern India: evolution and origin. Clim Dyn 37:957970. https://doi.org/10.1007/s00382-010-0879-y

Boos WR, Kuang Z (2010) Dominant control of the South Asian Monsoon by orographic insulation versus plateau heating. Nature 463:218-222. https://doi.org/10.1038/nature08707

Chen TC, Baker WE (1986) Global diabatic heating during FGGE SOP-1 and SOP-2. Mon Wea Rev 114(12):2578-2589

Chou C (2003) Land-sea heating contrast in an idealized Asian summer monsoon. Clim Dyn 21:11-25. https://doi.org/10.1007/ s00382-003-0315-7

Cui YF, Duan AM, Liu YM, Wu GX (2015) Interannual variability of the spring atmospheric heat source over the Tibetan Plateau forced by the North Atlantic SSTA. Clim Dyn 45:1617-1634. https://doi. org/10.1007/s00382-014-2417-9

Dai AG, Li HM, Sun Y, Hong L-C, LinHo CC, Zhou TJ (2013) The relative roles of upper and lower tropospheric thermal contrasts and tropical influences in driving Asian summer monsoons. J Geophys Res D 118:7024-7045. https://doi.org/10.1002/jgrd.50565

de Kok RJ, Immerzeel WW (2019) The Western Tibetan Vortex as an emergent feature of near-surface temperature variations. Geo Res Lett 46:14145-14152. https://doi.org/10.1029/2019GL085757

Dee DP, Uppala SM, Simmons AJ et al (2011) The ERA-Interim reanalysis: configuration and performance of the data assimilation system. Q J R Meteorolo Soc 137:553-597. https://doi.org/10. 1002/qj.828

Ding YH (1992) Effect of the Qinghai-Xizang (Tibetan) Plateau on the circulation features over the plateau and its surrounding areas. Adv Atmos Sci 9:112-130

Duan AM, Liu YM, Wu GX (2005) Heating status of the Tibetan Plateau from April to June and rainfall and atmospheric circulation anomaly over East Asia in midsummer. Sci China Ser D: Earth Sci 48(02):250-257

Duan AM, Wang MR, Lei YH, Cui YF (2013) Trends in summer rainfall over China associated with the Tibetan Plateau sensible heat source during 1980-2008. J Clim 26:261-275. https://doi.org/10. 1175/JCLI-D-11-00669.1

Feng X, Liu C, Rasmussen R, Fan G (2014) A 10-yr climatology of Tibetan Plateau vortices with NCEP climate forecast system reanalysis. J Appl Meteorol Climatol 53:34-46. https://doi.org/ 10.1175/JAMC-D-13-014.1

Flohn H (1957) Large-scale aspects of the 'summer monsoon' in South and East Asia. J Meteorol Soc Jpn 35:180-186

Forsythe N, Fowler HJ, Li XF, Blenkinsop S, Pritchard D (2017) Karakoram temperature and glacial melt driven by regional atmospheric circulation variability. Nat Clim Change 7:664-670. https:// doi.org/10.1038/NCLIMATE3361

Gao YX, Tang MC, Luo SW, Shen ZB, Li C (1981) Some aspects of recent research on the Qinghai-Xizang Plateau meteorology. Bull Amer Meteor Soc 62(1):31-35

Gill AE (1980) Some simple solutions for heat-induced tropical circulation. Quart J Roy Meteor Soc 106:447-462

Hahn DG, Manabe S (1975) The role of mountains in the South Asian Monsoon circulation. J Atmos Sci 32(8):1515-1541

He HY, Mcginnis JW, Song ZS, Yanai M (1987) Onset of the Asian Summer Monsoon in 1979 and the effect of the Tibetan Plateau. Mon Wea Rev 115(9):1966-1995

Hersbach H, Dee D (2016) "ERA-5 reanalysis is in production", ECMWF newsletter, number 147, Spring 2016, p. 7, 2016.

Hoskins BJ, Rodwell MJ (1995) A model of the Asian summer monsoon. I, The global scale, J Atmos Sci 52:1329-1340

Kawamura R, Fukuta Y, Ueda H, Matsuura T, Iizuka S (2002) A mechanism of the onset of the Australian summer monsoon. J Geophys Res 107(D14):4204. https://doi.org/10.1029/2001JD001070

Koch P, Wernli H, Davies HC (2006) An event-based jet-stream climatology and typology. Int J Climatol 26:283-301. https://doi. org/10.1002/joc. 1255

Kuo HL, Qian YF (1981) Influence of the Tibetian Plateau on cumulative and diurnal changes of weather and climate in summer. Mon Wea Rev 109(11):2337-2356

Li CY, Wang JT, Lin SZ, Cho HR (2004) The relationship between East Asian summer monsoon activity and northward jump of the upper westerly jet location (in Chinese). Chinese J Atmos Sci 28:641-658

Li CY, Pan J (2006) Atmospheric circulation characteristics associated with the onset of Asian summer monsoon. Adv Atmos Sci 23:925-939

Li CF, Yanai M (1996) The onset and interannual variability of the Asian summer monsoon in relation to land-sea thermal contrast. J Clim 9:358-375

Li J, Yu R, Zhou T (2008) Teleconnection between NAO and climate downstream of the Tibetan Plateau. J Clim 21:4680-4690. https:// doi.org/10.1175/2008JCLI2053.1

Li XF, Fowler HJ, Forsythe N, Blenkinsop S, Pritchard D (2018) The Karakoram/Western Tibetan vortex: seasonal and year-to-year variability. Clim Dyn 51:3883-3906. https://doi.org/10.1007/ s00382-018-4118-2

Li XF, Fowler HJ, Yu JJ, Forsythe N, Blenkinsop S, Pritchard D (2019) Thermodynamic controls of the Western Tibetan Vortex on Tibetan air temperature. Clim Dyn 53:4267-4290. https://doi. org/10.1007/s00382-019-04785-2

Liebmann B, Smith CA (1996) Description of a complete (interpolated) outgoing longwave radiation dataset. Bull Amer Meteor Soc 77:1275-1277

Liu XD, Yanai M (2001) Relationship between the Indian monsoon precipitation and the tropospheric temperature over the Eurasian continent. Quart J Roy Meteor Soc 127(573):909-937

Liu XD, Yin ZY (2002) Sensitivity of East Asian monsoon climate to the uplift of the Tibetan Plateau. Palaeogeogr Palaeoclimatol Palaeoecol 183:223-245

Luo HB, Yanai M (1984) The large-scale circulation and heat sources over the Tibetan Plateau and surrounding areas during the early summer of 1979. part ii: heat and moisture budgets. Mon Wea Rev 112:966-989 
Minoura D, Kawamura R, Matuura T (2003) A mechanism of the onset of the South Asian summer monsoon. J Meteorol Soc Jpn 81(3):563-580

Nitta T (1983) Observational study of heat sources over the eastern Tibetan Plateau during the summer monsoon. J Meteorol Soc Jpn 61:606-618

Prasad VS, Hayashi T (2005) Onset and withdrawal of Indian summer monsoon. Geophys Res Lett 32:L20715. https://doi.org/10.1029/ 2005GL023269

Qian ZA, Shan FM, Lv JN, Cai YX, Chen YC (1984) Statistics of Qinghai-Xizang Plateau vortices for the summer of 1979 and discussions of the climatological factors for the vortex genesis (in Chinese). Collected Works of QXPMEX(II), Science Press, pp 182-194.

Randel WJ, Park M (2006) Deep convective influence on the Asian summer monsoon anticyclone and associated tracer variability observed with atmospheric infrared sounder (AIRS). J Geophys Res 111:D12314. https://doi.org/10.1029/2005JD006490

Ren XJ, Yang XQ, Chu CJ (2010) Seasonal variations of the synopticscale transient eddy activity and polar front jet over East Asia. J Clim 23(12):3222-3233. https://doi.org/10.1175/2009JCLI3225.1

Rowson DR, Colucci SJ (1992) Synoptic climatology of thermal lowpressure systems over south-western north America. Int J Climatol 529-545.

Seto R, Koike T, Rasmy M (2013) Analysis of the vertical structure of the atmospheric heating process and its seasonal variation over the Tibetan Plateau using a land data assimilation system. J Geophys Res D: Atmos 118:12403-12421. https://doi.org/10.1002/2013J D020072

Smith RK, Spengler T (2011) The dynamics of heat lows over elevated terrain. Quart J Roy Meteor Soc 137:250-263. https://doi.org/10. 1002/qj.737

Tamura T, Taniguchi K, Koike T (2010) Mechanism of upper tropospheric warming around the Tibetan Plateau at the onset phase of the Asian summer monsoon. J Geophys Res 115. https://doi. org/https://doi.org/10.1029/2008jd011678

Taniguchi K, Koike T (2007) Increasing atmospheric temperature in the upper troposphere and cumulus convection over the eastern part of the Tibetan Plateau in the pre-monsoon season of 2004. J Meteorol Soc Jpn 85A:271-294

Ueda H, Kamahori H, Yamazaki N (2003) Seasonal contrasting features of heat and moisture budgets between the eastern and western Tibetan Plateau during the GAME IOP. J Clim 16(14):2309-2324

Wang AH, Zeng X (2012) Evaluation of multi reanalysis products with in situ observations over the Tibetan Plateau. J Geophys Res 117:D05102. https://doi.org/10.1029/2011JD016553
Wang B, Bao Q, Hoskins B, Wu GX, Liu YM (2008) Tibetan Plateau warming and precipitation changes in East Asia. Geophys Res Lett 35(14):L14702. https://doi.org/10.1029/2008GL034330

Wu GX, Liu YM, Zhang Q, Duan AM, Wang TM, Wan RJ, Liu X, Li WP, Wang ZZ, Liang XY (2007) The influence of mechanical and thermal forcing by the Tibetan Plateau on Asian climate. J Hydrometeorol 8:770-789. https://doi.org/10.1175/JHM609.1

Wu GX, He B, Liu YM, Bao Q, Ren RC (2015) Location and variation of the summertime upper-troposphere temperature maximum over South Asia. Clim Dyn 45:2757-2774. https://doi.org/10.1007/ s00382-015-2506-4

Yanai M, Esbensen S, Chu JH (1973) Determination of bulk properties of tropical cloud clusters from large-scale heat and moisture budget. J Atmos Sci 30:611-627

Yanai M, Li CF, Song ZS (1992) Seasonal heating of the Tibetan Plateau and its effects on the evolution of the Asian summer monsoon. J Meteorol Soc Jpn 70(1B):319-351

Yanai M, Li CF (1994) Mechanism of heating and the boundary layer over the Tibetan Plateau. Mon Wea Rev 122:305-323

Ye DZ, Gao YX (1979) Meteorology of the Tibetan Plateau (in Chinese). Science Publication Agency, pp 278.

Ye DZ, Luo SW, Zhu BZ (1957) The wind structure and heat balance in the lower troposphere over Tibetan Plateau and its surroudings. Acta Meteor Sin 2(2):108-121

Zhao P, Zhu Y, Zhang R (2007) An Asian-Pacific teleconnection in summer tropospheric temperature and associated Asian climate variability. Clim Dyn 29:293-303. https://doi.org/10.1007/ s00382-007-0236-y

Zhao Y, Duan AM, Wu GX (2018) Interannual variability of latespring circulation and diabatic heating over the Tibetan Plateau associated with Indian ocean forcing. Adv Atmos Sci 35: 927 941. https://doi.org/10.1007/s00376-018-7217-4

Zheng QL, Liou KN (1986) Dynamic and thermodynamic influences of the Tibetan Plateau on the atmosphere in a general circulation model. J Atmos Sci 43(13):1340-1355

Zheng QL, Liang F (1999) Numerical study on influence of the Qinghai-Xizang Tibetan Plateau on the seasonal transition of the globe atmospheric circulation (in Chinese). J Trop Meteorol 15(3):247-257

Publisher's Note Springer Nature remains neutral with regard to jurisdictional claims in published maps and institutional affiliations. 